\title{
Aquaporin water channels in the nervous system
}

\author{
Marios C. Papadopoulos ${ }^{1}$ and Alan S. Verkman ${ }^{2}$ \\ ${ }^{1}$ Academic Neurosurgery Unit, St. George's, University of London, Tooting, London, SW17 ORE, \\ UK \\ ${ }^{2}$ Departments of Medicine and Physiology, University of California, San Francisco, California \\ 94143, USA
}

\section{Abstract}

The aquaporins (AQPs) are plasma membrane water-transporting proteins. AQP4 is the principal member of this protein family in the CNS, where it is expressed in astrocytes and is involved in water movement, cell migration and neuroexcitation. AQP1 is expressed in the choroid plexus, where it facilitates cerebrospinal fluid secretion, and in dorsal root ganglion neurons, where it tunes pain perception. The AQPs are potential drug targets for several neurological conditions. Astrocytoma cells strongly express AQP4, which may facilitate their infiltration into the brain, and the neuroinflammatory disease neuromyelitis optica is caused by AQP4-specific autoantibodies that produce complement-mediated astrocytic damage.

The aquaporins (AQPs) are a family of small, integral membrane transport proteins and their primary function is to facilitate water movement across cell membranes in response to osmotic gradients. The first member of this family, AQP1 (originally known as CHIP28), was identified in erythrocytes in 1991 (REF. 1). This discovery led to homology cloning of hundreds of AQP homologues from throughout the animal and plant kingdoms, as well as from lower organisms ${ }^{2-5}$. In humans and rodents, there are 14 AQPs and at least eight of these have been shown to transport water. A subset of AQPs called aquaglyceroporins, which include AQP3, AQP7 and AQP9, also transport glycerol and, in the case of AQP9, perhaps some small polar solutes ${ }^{6,7}$. Under some conditions, certain AQPs may transport various gases $\left(\mathrm{CO}_{2}, \mathrm{NH}_{3}, \mathrm{NO}\right.$ and $\left.\mathrm{O}_{2}\right)$, small solutes $\left(\mathrm{H}_{2} \mathrm{O}_{2}\right)$ and ions $\left(\mathrm{K}^{+}\right.$and $\left.\mathrm{Cl}^{-}\right)$, although the biological importance of gas, solute and ion transport by mammalian AQPs is unclear $^{8}$. In general, gas permeability is not limited by the intrinsic cell membrane permeability but by diffusion in so-called 'unstirred layers' outside the membrane ${ }^{9}$. Water transport is the primary function of the main AQPs in the CNS, namely AQP1 and AQP4.

This Review examines the expression and function of AQPs in the mammalian nervous system, focusing on the cellular mechanisms by which AQPs affect CNS functions. In addition, AQP-related CNS diseases - including neuromyelitis optica (NMO), involving astrocyte damage that is mediated by AQP4-specific antibodies — and potential AQP-

(C) 2013 Macmillan Publishers Limited. All rights reserved

Correspondence to M.C.P. mpapadop@sgul.ac.uk.

Competing interests statement

The authors declare no competing financial interests.

DATABASES

RCSB Protein Data Bank: http://www.rcsb.org/3GD8

FURTHER INFORMATION

Alan S. Verkman's homepage: www.ucsf.edu/verklab

ALL LINKS ARE ACTIVE IN THE ONLINE PDF 
targeted therapeutics are discussed. AQPs are also expressed widely outside the nervous system in epithelia, microvascular endothelia, epidermis, immune cells, adipocytes, skeletal muscle and other tissues, and the reader is referred to recent reviews for more information about these non-nervous system functions of AQPs and their underlying cellular mechanisms ${ }^{2,3}$.

\section{AQP structure}

AQP monomers are $\sim 30 \mathrm{kDa}$ and, in general, contain six membrane-spanning helical segments and two shorter helical segments that do not span the entire membrane ${ }^{10}$ (FIG. 1a). The AQPs generally form stable tetramers in membranes, although each monomer contains a separate water pore. High-resolution structural data show that the membrane-spanning helical domains surround cytoplasmic and extracellular vestibules that are connected by a narrow aqueous pore ${ }^{11}$ (FIG. 1b). Structural data and molecular dynamics simulations suggest that water molecules move through this narrow aqueous pore and that steric and electrostatic factors are responsible for the water selectivity of AQPs ${ }^{12,13}$. The pore is less constricted in the aquaglyceroporins than in the water-selective AQPs (diameter of $3.4 \AA$ versus $2.8 \AA$, respectively) and is lined by more hydrophobic residues.

Interestingly, AQP4 can form crystal-like supramo-lecular assemblies in the plasma membrane, which are called orthogonal arrays of particles (OAPs). OAPs have been visualized by freeze-fracture electron microscopy in AQP4-transfected cells ${ }^{14}$ and have been found in the brain and other tissues in wild-type but not Aqp4 deficient mice ${ }^{15}$. Labelling of OAPs by AQP4-specific antibodies has allowed their visualization by immunogold electron microscopy ${ }^{16,17}$ and, recently, by super-resolution fluorescence microscopy ${ }^{18}$ (FIG. 1c). AQP4 is present as two major isoforms that are produced by alternative splicing: the relatively long M1 isoform, which is generated by translation initiation at Met1, and a shorter M23 isoform, which is generated by translation initiation at Met23 (FIG. 1a). The M1 and M23 isoforms of AQP4 associate in membranes as heterotetramers ${ }^{17,19,20}$ and aggregate into OAPs through M23-M23 interactions, involving hydrophobic residues just downstream of Met23 (REF. 21). The biological importance of OAP formation by AQP4 is unknown. It has been speculated that OAPs enhance water permeability ${ }^{22}$ and might be involved in cell-cell adhesion ${ }^{23}$, but these hypotheses have been refuted experimentally 24,25 . OAPs might also be involved in AQP4 polarization in astrocyte foot processes (see below) ${ }^{26}$. Interestingly, as discussed later, AQP4 OAPs have a crucial role in the pathophysiology of NMO.

\section{AQP expression in the nervous system}

$\mathrm{AQP}$ expression has been studied more intensively in the CNS and sensory organs than in the peripheral and enteric nervous systems. The expression pattern of AQPs in the nervous system is summarized in FIG. 2.

\section{CNS}

AQP4 is the most abundant water channel in the brain ${ }^{27}$, spinal cord ${ }^{28}$ and optic nerve ${ }^{29}$. Although AQP4 is widely expressed in the astrocyte cell plasma membrane, it is primarily localized to specific regions, such as astrocyte foot processes ${ }^{17,30}$. This polarized expression of AQP4 may result from intracellular interactions between this channel and a-syntrophin ${ }^{31}$ or through extracellular AQP4 interactions with agrin ${ }^{32}$; like AQP4, a-syntrophin and agrin show polarized expression in astrocyte foot processes ${ }^{33}$. Intercellular astrocyte contacts with endothelial and pial cells may also be important for AQP4 polarization, as loss of these contacts abolishes the polarized expression pattern ${ }^{34-36}$. It has been suggested that OAPs 
facilitate AQP4 polarization, because a single link is required to tether an entire AQP4 array to the plasma membrane, whereas scattered AQP4 tetramers each require a tether ${ }^{26}$.

In the brain, AQP4 is primarily localized to the subpial astrocyte processes that form the glial-limiting membrane (which acts as the CNS-cerebrospinal fluid (CSF) interface), the perivascular astrocyte endfeet (which are found at the CNS-blood interface) and the basolateral membrane of ependymal cells and subependymal astrocyte processes (which form the CNS-CSF interface) ${ }^{17,30}$. This pattern of AQP4 expression at the borders between the brain and major water-containing compartments suggests that AQP4 facilitates the flow of water into and out of the brain. In parts of the brain, including the circumventricular organs (which lack a blood-brain barrier (BBB)) ${ }^{17,30}$ and the hippocampus ${ }^{37}$, AQP4 is expressed throughout the astrocyte cell plasma membrane. The absence of perivas-cular astrocyte foot processes in the circumventricular organs may explain the relatively nonpolarized distribution of AQP4 in these structures. In the hippocampus, AQP4 is expressed within CA1 and the dentate gyrus, where it may facilitate the rapid water fluxes that are required for maintaining $\mathrm{K}^{+}$homeostasis during electrical activity ${ }^{38-40}$. A detailed discussion of the role of AQP4 in $\mathrm{K}^{+}$homeostasis is given below.

AQP1 is found in the ventricular-facing cell plasma membrane of choroid plexus epithelial cells ${ }^{41,42}$, suggesting a role for this channel in CSF secretion. AQP1 is also expressed in vascular endothelial cells throughout the body but is notably absent in the cerebrovascular endothelium ${ }^{41}$, except in circumventricular organs ${ }^{43}$. Cerebrovascular endothelial cells express AQP1 in culture ${ }^{44}$ and when the BBB is disrupted in malignant brain tumours ${ }^{45}$. Co-culture with astrocytes suppresses Aqp1 mRNA expression in primary brain microvessel endothelial cells ${ }^{44}$. These findings suggest that interactions between astrocyte foot processes and endothelial cells inhibit endothelial AQP1 expression.

AQP9 is weakly expressed in the brain ${ }^{46}$, but its localization is unclear because the available antibodies against this channel exhibit poor specificity. Expression of AQP9 has been reported in neurons of the substantia nigra, tanycytes and some astrocytes.

In the spinal cord, AQP4 is primarily localized in perivascular astrocyte foot processes and in the glial-limiting membrane, AQP1 is expressed in processes of non-myelinated neurons in the dorsal horns, and AQP9 may be expressed in spinal cord radial astrocytes and in the glial-limiting membrane ${ }^{28,47}$. As in the brain and spinal cord, the optic nerve expresses AQP4 primarily in perivascular astrocyte foot processes and in the glial-limiting membrane ${ }^{29}$. AQP4 is also expressed in astrocyte processes in regions of the CNS without a $\mathrm{BBB}$, including the pre-laminar optic nerve head ${ }^{48}$, the circumventricular organs ${ }^{49}$ and the root entry zones in the spinal cord ${ }^{50}$. This CNS AQP4 pool is thus exposed to the periphery and may be the initial target of circulating AQP4-specific antibodies in NMO (discussed below $)^{51,52}$.

\section{Peripheral nervous system}

In dorsal root ganglia, AQP1 colocalizes with substance $\mathrm{P}$ and the capsaicin receptor TRPV1 (transient receptor potential cation channel subfamily V member 1) in a subpopulation of neuronal C-fibres ${ }^{47,53}$. AQP1 is also expressed in neurons of the trigeminal ganglion that mediate nociception from the head. Consistent with these observations, AQP1 is expressed in the dorsal horns of the spinal cord, specifically in laminae associated with nociception ${ }^{28}$. There are a few isolated reports of AQP1 expression in other parts of the peripheral nervous system, including in the sciatic nerve 28,54 and the periodontal Ruffini mechanoreceptors ${ }^{55}$. 


\section{Sensory organs}

AQP4 is expressed in retinal glia (which are called Müller cells) ${ }^{56}$, supporting cells in olfactory epithelium ${ }^{57}$, and Claudius cells, Hensen cells and inner sulcus cells of the organ of Corti in the inner ear ${ }^{58}$; however, it is absent from excitable cells in these tissues. This is an analogous situation to that in the CNS, where AQP4 is found in astrocytes but not in neurons. Of note, AQP1 is also expressed in the fibrocytes of the spiral ligament in the inner ear ${ }^{58}$.

Various AQPs can be detected in the eye. AQP1 is expressed in the corneal endothelium, keratocytes and the ciliary epithelium. AQP4 is expressed in the ciliary epithelium. By contrast, AQP3 is expressed in the conjunctival epithelium and, together with AQP5, the corneal epithelium. Finally, AQP0 expression is detectable in lens fibre cells. This expression pattern suggests that AQPs are involved in intraocular pressure regulation, corneal and lens transparency, and corneal and conjunctival barrier function (see REF. 59 and papers cited therein for further description of ocular AQP expression and functional data from Aqp knockout mice).

\section{Enteric nervous system}

The enteric nervous system comprises neurons and glia in the submucosal and myenteric plexuses, which regulate solute absorption and gastrointestinal motility. AQP1 has been detected in glia in human oesophageal neurons ${ }^{54}$ and rat ileal neurons ${ }^{60}$ in the submucosal and myenteric plexuses, as well as in sub-mucosal neurons of sheep duodenum ${ }^{61}$. AQP4 has been detected in rat and mouse myenteric and submucosal neurons ${ }^{62}$. Increased AQP1 expression in ileal neurons of diabetic rats has suggested that AQP1 may be involved in diabetic gastrointestinal dysfunction ${ }^{63}$. No functional data exist for the involvement of AQP1 or AQP4 in mucosal solute transport or gastrointestinal motility.

\section{Spine}

The intervertebral disc consists of a gelatinous core, the nucleus pulposus, which acts as a shock absorber and is surrounded by a tough annulus fibro-sus. AQP1 and AQP3 are expressed in chondrocyte-like cells that reside within the nucleus pulposus ${ }^{64}$. As dehydration of the nucleus pulposus is a characteristic feature of degenerated discs, it has been suggested that AQPs might play a part in degenerative disc disease, which is a common cause of back pain ${ }^{64}$. The expression of AQP9 in osteoclasts ${ }^{65}$ has suggested a role for this channel in bone resorption and osteoporosis. However, no functional studies have been conducted to test these ideas.

\section{AQP functions in the nervous system}

Knowledge of AQP functions in the nervous system is largely derived from experiments subjecting Aqp knockout mice to different pathological conditions, as to date there are no selective, non-toxic AQP inhibitors, and humans with loss-of-function mutations in AQP4 have not been identified. At least three groups have generated Aqp 4 deficient mice (BOX 1) and identified major roles for AQPs in facilitating water movement into and out of the CNS, astrocyte migration and neuroexcitation. When interpreting the mouse data, some differences between the CNS of rodents and primates should be noted. Neurons outnumber astrocytes by 3 to 1 in mouse and rat cerebral cortex, but in human cerebral cortex, astrocytes outnumber neurons by 1.4 to 1 (REF. 66). Furthermore, AQP1, which is not expressed in mouse astrocytes in vivo, has been detected in some astrocytes in monkey brain ${ }^{67}$. Together, these observations suggest that AQPs may have more important roles in the primate CNS than in the rodent CNS. 


\section{Box 1}

\section{Aquaporin 4 knockout mice}

The first aquaporin $4(A q p 4)$ knockout mouse line was generated by Verkman's group in San Francisco, USA ${ }^{145}$. This line was followed by an Aqp4 knockout mouse line generated by Hu's group in Nanjing, China ${ }^{146}$ and, later, a line made by the group of Ottersen and Nagelhus in Oslo, Norway; in these latter mice, Aqp4 could be conditionally deleted in glia only, thereby preserving AQP4 expression in peripheral organs $^{72}$. In general, Aqp4 knockout mice have normal brain vascular anatomy (San Francisco) ${ }^{79}$, gross appearance, neuronal, astrocyte and oligodendrocyte characteristics and blood-brain barrier (BBB) integrity (San Francisco and Oslo) ${ }^{72,147}$. Indeed, the findings from the San Francisco and Oslo Aqp4 knockout mice are remarkably similar. The Nanjing Aqp4 knockout mice have marked abnormalities including disruption of the $\mathrm{BBB}$, which allows large proteins to pass through it, and therefore data from these mice should be interpreted with caution ${ }^{146}$. Compared with wild-type mice, Aqp4 knockout mice show mild extracellular space volume expansion (San Francisco) ${ }^{148-150}$, slightly increased brain water content (San Francisco and Oslo) ${ }^{27,72}$, reduced perivascular expression of a-syntrophin and dystrophin (Oslo) ${ }^{151}$ and reduced expression of excitatory amino acid transporter 2 (EAAT2; also known as GLT1 and SLC1A2), which is a glutamate transporter (Nanjing) ${ }^{152}$. Isolated reports have shown that $A q p 4$ knockout mice have reduced neuroinflammation (San Francisco) ${ }^{153}$, impairment of long-term potentiation (San Francisco) ${ }^{154}$, impairment in astrocyte cell volume regulation (Oslo) ${ }^{155}$ and a series of neurochemical, neuronal and behavioural abnormalities (Nanjing) ${ }^{156,157}$. It has also been suggested that AQP4 may facilitate the uptake of amyloid- $\beta$ into astrocytes (Nanjing) ${ }^{158}$ and AQP9 may facilitate the uptake of MPTP (1-methyl-4phenyl-1,2,3,6-tetrahydropyridine) into substantia nigra neurons (Oslo $)^{159}$. In general, studies conducted in knockout mice are potentially confounded by altered expression of many genes. Thus, it is not known whether the apparent differences between Aqp4 knockout and wild-type mice are a primary or secondary consequence of Aqp4 deletion.

\section{Water movement}

The intracranial cavity in adults comprises several compartments (that is, blood, CSF and brain parenchyma intracellular and interstitial spaces) and is surrounded by the nondistensible skull. Water flows between these compartments in response to osmotic and hydrostatic forces. Although water molecules can cross the cell plasma membrane directly and perhaps to a small extent through some glucose transporters and ion channels ${ }^{68,69}$, several studies support a major role for AQP4 in determining BBB water permeability. $A q p 4$ deletion is associated with a sevenfold reduction in cell plasma membrane water permeability in cultured astrocytes ${ }^{35}$ and a tenfold reduction in BBB water permeability in mouse brain ${ }^{70}$. Reducing AQP4 protein expression with small interfering RNAs (siRNAs) by $27 \%$ in the rat brain caused a $50 \%$ decrease in the apparent diffusion coefficient, which is consistent with reduced astrocyte cell plasma membrane water permeability ${ }^{71}$.

Nevertheless, Aqp4 null mice have normal intracranial pressure ${ }^{27}$ and only slightly increased total brain water content ${ }^{27,72}$. These findings suggest that AQP4 is not needed for relatively slow water movements into and out of the brain that take place under normal physiological conditions, as these can occur through AQP4-independent pathways. In CNS diseases (such as brain injury, meningitis, brain tumours and hydrocephalus), the rates of water flow into and out of the brain rise, causing increased intracranial pressure from excess water accumulation in intracranial compartments. Increased intracranial pressure is detrimental, as it causes brain ischaemia, herniation and, ultimately, brain death (for 
reviews, see REFS 73,74). AQP4 thus facilitates water transport into and out of the brain in these CNS diseases.

Several descriptive studies show that changes in brain AQP4 expression correlate with the amount of brain oedema in human and rodent diseases ${ }^{70,75-78}$, suggesting that this channel has a role in brain oedema. However, the spatial and temporal patterns of AQP4 expression are complicated, such that it is unclear from these studies whether increased AQP4 expression exacerbates brain oedema or facilitates oedema fluid clearance. AQP4 is upregulated in cerebral contusion, bacterial meningitis and subarachnoid haemorrhage, thus potentially amplifying its contribution to brain oedema formation or elimination ${ }^{70,75-78}$.

Studies of Aqp4 knock out in mouse models of various CNS diseases also support a role of AQP4 in water transport. There is less brain oedema in Aqp4 knockout than in wild-type mice after focal cerebral ischaemia, water intoxication ${ }^{72,79}$ or bacterial meningitis ${ }^{70}$. Mice lacking a-syntrophin ${ }^{80}$ or dystrophin ${ }^{81}$, which show AQP4 mis-localization on the surface of astrocytes, also develop less brain oedema than wild-type mice after water intoxication or focal cerebral ischaemia. However, the presence of abnormalities in the brains of the $a-$ syntrophin knockout mice (which have swollen astrocyte endfeet) ${ }^{80}$ and dystrophin knockout mice (which have open tight junctions, degenerating microvessels and swollen astrocyte endfeet $)^{82}$ confound the interpretation of these findings. Aqp4 null mice also develop less spinal cord oedema after transient cord compression ${ }^{83}$. The mouse models of water intoxication, focal cerebral ischaemia, bacterial meningitis and spinal cord compression (which is associated with ischaemic cord damage) generate a blood-CNS osmotic gradient from serum hypo-osmolality (in the case of water intoxication) or energy failure (in the case of ischaemia and meningitis) that drives water flow from the blood into the brain cells, causing cytotoxic oedema. These findings suggest that, in wild-type mice, the excess water enters the CNS through AQP4 channels, with reduced water entry in Aqp4 knockout mice ${ }^{83}$ (FIG. 3). Reduced cytotoxic brain oedema (and downstream signalling) has also been found in glia-specific Aqp4 knockout mice following water intoxication ${ }^{84}$, and increased cytotoxic oedema was found in AQP4-overexpressing transgenic mice ${ }^{85}$. AQP4 is thus the rate-limiting step for water flow from the blood into the CNS in diseases associated with oedema in which the BBB is intact.

In models of disease involving BBB disruption, including brain tumour ${ }^{27}$, brain abscess ${ }^{86}$, subarach-noid haemorrhage ${ }^{87}$ and status epilepticus ${ }^{88}$, Aqp4 null mice develop more brain oedema than wild-type mice. Increased oedema in Aqp4 null mice was also seen after contusion spinal cord injury ${ }^{89}$, which disrupts the blood-spinal cord barrier. Microinfusion of saline directly into brain extracellular space (ECS) produced a greater increase in intracranial pressure in Aqp4 knockout than in wild-type mice ${ }^{27}$. In these models, hydrostatic forces drive water and solutes from the blood through the disrupted BBB into the ECS independent of AQP4 (this is called vasogenic oedema). Although the rate of brain or spinal cord water entry is similar in wild-type and Aqp4 null mice, the greater water accumulation in the latter suggests that elimination of vasogenic oedema fluid is AQP4dependent.

Two theories of AQP4-dependent vasogenic oedema fluid clearance from the CNS have been proposed, and both involve AQP4-dependent transcellular water flow. In one theory, water elimination occurs across three AQP4-rich interfaces (through the ependyma into the ventricular CSF, the subpial astrocytes into the subarach-noid CSF and the BBB into the blood) and is driven by hydrostatic pressure 27 (FIG. 3). According to the other theory, excess water flows through the brain parenchyma, transcellularly through AQP4, into perivenous spaces and then along veins. The fluid is then eliminated into cervical lymphatics and through arachnoid granulations into the blood 90 . A problem with both theories is that 
the flow of solute-free water through AQP4 would be opposed by the osmotic gradients created between the intracellular and extracellular spaces as well as between the intracellular space and the CSF.

AQP1 plays a part in CSF secretion and AQP4 in CSF absorption. CSF is secreted by the choroid plexus and is absorbed primarily through arachnoid granulations into the venous sinuses and by other routes such as transependymal flow into the brain. CSF secretion involves the active transport of $\mathrm{Na}^{+}$from the blood into the ventricles, which generates an osmotic gradient that drives the flow of water. AQP1 is expressed in the apical (ventricularfacing) surface of the choroid plexus epithelium ${ }^{41}$. Compared with wild-type mice, Aqp1 knockout mice have fivefold reduced osmotic water permeability in the choroid plexus and $50 \%$ lower intracranial pressure. The CSF secretion rate is reduced by only 25\% in Aqp1 deficient mice compared with wild-type mice, which suggests that only part of CSF secretion is AQP1-dependent and the rest is through non-AQP1-dependent pathways ${ }^{42}$. The presence of AQP4 in ependymal cells and subependymal astrocytes is an important determinant of CSF flow across the ventricle-brain interface. Indeed, reduced transependymal CSF flow into the brain parenchyma and reduced CSF absorption across the BBB into the blood may account for the sporadic hydrocephalus observed in Aqp4 null mice $^{91}$ and the accelerated progression of obstructive hydrocephalus in AQP4 deficiency produced by cisternal kaolin injection ${ }^{92}$. The increased AQP4 expression observed in human and rodent hydrocephalus ${ }^{78}$ may be a compensatory response to facilitate CSF elimination through the transependymal route.

\section{Astrocyte migration}

An unexpected role for AQPs in cell migration was suggested in a study in which localized micropipette delivery of $\mathrm{Hg}^{2+}$ or small polyethylene glycols impaired neutrophil motility, perhaps by reducing water flow through AQP9 (REF. 93). Another study using Aqp1 knockout mice showed that microvascular endothelial cells from such animals migrated more slowly than those from wild-type mice and, indeed, that the slower migration of these cells accounted for the impaired angiogenesis observed in the knockout animals ${ }^{94}$. AQPfacilitated cell migration was subsequently reported in a wide variety of immune, epithelial, tumour and other cell types ${ }^{95}$. In a mouse model of tumour cell metastasis, AQP expression in tumour cells was shown to increase their extravasation across blood vessels and their local invasiveness ${ }^{96}$.

In migrating astrocytes, AQP4 expression mainly occurs at the leading edge of such cells and hence is largely polarized ${ }^{97}$. Compared with astrocytes from wild-type mice, astrocytes from Aqp4 knockout mice showed slowed migration in in vitro transwell and wound healing assays, but they did not exhibit impairments in cell proliferation or adhesion. In vivo, glial scar formation was impaired in Aqp4 knockout mice following stab injury ${ }^{97}$. In addition, following injection into the brains of wild-type mice, fluorescently labelled wild-type astrocytes migrated faster than fluorescently labelled $A q p 4$ deficient astrocytes ${ }^{98}$. AQP4dependent astrocyte migration may thus facilitate glial scar formation.

In one proposed mechanism for AQP-dependent astrocyte migration, AQP-facilitated water transport at the leading edge of migrating astrocytes increases their lamellipodial extension (FIG. 4a). According to this mechanism, actin depolymerization and/or active solute influx in lamellipodia creates an osmotic gradient that drives water influx across the cell's plasma membrane. The resultant increase in hydrostatic pressure causes local expansion of the plasma membrane, which is followed by actin re-polymerization to stabilize the cell membrane protrusion. The observation that regional hydrostatic pressure changes within cells do not equilibrate in the cytoplasm on scales of 10 microns and 10 seconds ${ }^{99}$ supports the possibility of pressure-induced formation of localized cell membrane protrusions. In 
support of the idea that AQP-dependent water flow occurs into and out of migrating astrocytes, the migration of such cells can be modulated by changes in extracellular osmolality and transcellular osmotic gradients ${ }^{97,100}$, AQP expression increases the migration in multiple cell types and with different AQPs, and AQP expression increases lamellipodial ruffling and dynamics ${ }^{94,97}$. However, direct support of this proposed mechanism will require measurement of water transport across lamellipodia in migrating cells. Alternative potential mechanisms to explain AQP-dependent cell migration include AQP-dependent changes in cell shape and volume during passage through tight environments and specific interactions between AQPs and components of the cell locomotion machinery 95,101 .

\section{Neuroexcitation}

A role for AQP4 in neural signal transduction was first proposed following the observation that deletion of a-syntrophin in mice is associated with severe hyperthermia-induced seizures and prolonged $\mathrm{K}^{+}$clearance ${ }^{40}$. Studies in knockout mice and brain slices have confirmed that AQP4 is involved in neural signal transduction and have provided mechanistic insights. Aqp 4 deficient mice have an increased threshold for seizure initiation with chemical ${ }^{102}$ or electrical ${ }^{38}$ stimulation and show prolonged seizure duration and altered $\mathrm{K}^{+}$reuptake kinetics ${ }^{38}$. In the intra- hippocampal kainic acid model of epileptogenesis, Aqp4 knockout mice exhibit an increase in the frequency of spontaneous seizures during the first week after status epilepticus ${ }^{103}$ (for a review of the role of AQP4 in seizures, see REF. 104).

With regard to neurosensory signal transduction, auditory signal-evoked responses are impaired in Aqp4 knockout mice ${ }^{58}$. Sound waves displace the stereocilia of inner hair cells, causing $\mathrm{K}^{+}$flow from the endolymph into the hair cell and consequent depolarization.

Supporting cells take up $\mathrm{K}^{+}$from the hair cells. Aqp 4 knockout mice have mildly impaired retinal function with reduced amplitude of $b$-waves (produced by bipolar cells), as detected by electroretinography ${ }^{56}$, which has been interpreted as impaired coupling of bipolar cell depolarization to Müller cell activation. Aqp4 knockout mice also have impaired olfaction, as shown in behavioural studies and by reduced electro-olfactogram voltage responses to odorants $^{57}$.

Delayed $\mathrm{K}^{+}$reuptake was initially demonstrated in a-syntrophin null mice ${ }^{40}$.

Microelectrode and fluorescence imaging studies in the brain in vivo and in brain slices of Aqp4 deficient mice also showed slowed accumulation of $\mathrm{K}^{+}$in the brain ECS during neuroexcitation ${ }^{38,105}$ and slowed clearance of $\mathrm{K}^{+}$from the ECS following neuroexcitation ${ }^{39,105}$. Slowed $\mathrm{K}^{+}$clearance from the ECS could account for the various neuroexcitation phenotypes, such as prolonged seizure duration, that are observed in Aqp4 knockout mice.

The mechanistic link between $\mathrm{K}^{+}$reuptake by astro-cytes and AQP4 water permeability is unclear. The ECS represents approximately $\sim 20 \%$ of total brain volume ${ }^{106} . \mathrm{K}^{+}$is released into the ECS by neurons in response to membrane depolarization during neuroexcitation and is mainly cleared through uptake by astrocytes, which involves the inwardly rectifying $\mathrm{K}^{+}$ channel Kir4.1 and other astrocyte $\mathrm{K}^{+}$transporters (FIG. 4b). One hypothesis to explain $\mathrm{K}^{+}-$ water coupling is a functional interaction between AQP4 and Kir4.1 (REFS 40,107); however, a patch-clamp study of astrocytes and Müller cells showed that AQP4 expression did not affect Kir4.1 function ${ }^{108}$. An alternative possibility is that uptake of $\mathrm{K}^{+}$following neuroexcitation results in osmotic water influx by astrocytes and, consequently, ECS shrinkage, which would maintain the electrochemical driving force for efficient $\mathrm{K}^{+}$reuptake (FIG. 4b). The reduction in astrocyte water permeability linked to AQP4 deficiency would impair ECS contraction and hence slow $\mathrm{K}^{+}$reuptake. This hypothesis, which is supported by mathematical modelling ${ }^{109}$, is attractive because it relates the neuroexcitation phenotypes 
directly to AQP4-mediated water transport. Nonetheless, at this time, the possibility that the neuroexcitation phenotypes resulting from the Aqp 4 deficiency can be explained by altered expression of genes other than $A q p 4$ cannot be excluded.

\section{Aquaporin functions in the peripheral nervous system}

Several studies have shown AQP1 expression in non-myelinated neurons in the dorsal root ganglia and their projections in the dorsal horns of the spinal cord $28,47,53$ (FIG. 2). An initial study reported that $A q p 1$ knockout mice showed reduced sensitivity for some painful stimuli applied to the paws (thermal stimuli and capsaicin) but not others (mechanical stimuli and formalin $^{53}$, suggesting that AQP1 has a role in the perception of pain. Another study, however, found that $A q p 1$ deletion had no effects on pain perception ${ }^{44}$. A subsequent study showed that $A q p 1$ knockout mice exhibit a selective reduction in thermal inflammatory- and cold-induced pain and provided biophysical evidence for an interaction between AQP1 and the voltage-gated $\mathrm{Na}^{+}$channel Nav1.8 (REF. 110). A patch-clamp study showed that $A q p 1$ deficient dorsal root ganglion neurons exhibited reduced action-potential firing in response to current injections, and experiments in the Nav1.8-expressing cell line ND7-23 showed that AQP1 expression altered $\mathrm{Na}_{\mathrm{V}} 1.8$ frequency-dependent inactivation. A functional interaction between AQP1 and an ion channel represents a mechanism of action for these channels that is quite different from their typical role in water and small solute transport. There are no functional data on the role of AQP1 in trigeminal ganglion neurons ${ }^{53}$ or in Ruffini mechanoreceptors ${ }^{55}$ in which this channel is expressed.

\section{Translational aspects of AQP neurobiology}

AQPs expressed in the CNS are novel therapeutic targets for brain oedema and epilepsy, as discussed above, and for NMO and astrocytomas, as discussed below.

\section{Neuromyelitis optica}

NMO is a rare inflammatory demy-elinating disease of the CNS that preferentially affects the optic nerves and spinal cord ${ }^{52,111}$, and causes blindness, paralysis and death. It was thought to be a variant of multiple sclerosis (MS) until 2004, when serum antibodies against a perivascular brain antigen were detected in individuals with NMO but not in patients with MS $^{112}$; these antibodies were subsequently shown to be against AQP4 (REF. 113). AQP4specific antibodies are now widely used to diagnose NMO and distinguish it from MS.

AQP4-specific antibodies in NMO are predominantly of the immunoglobulin G1 (IgG1) subtype and bind three-dimensional conformational epitopes on the extracellular loops of AQP4, producing astrocyte damage by complement-dependent cytotoxicity (FIG. 5). The AQP4-specific IgG epitopes appear to be located in all three extracellular loops of AQP4 (REFS 114-116). It was initially reported that AQP4-specific IgG binds to OAPs exclusively ${ }^{117}$, but it is now known that AQP4-specific IgG binds to both individual AQP tetramers and OAPs, although generally with higher affinity to OAPs ${ }^{18-120}$. AQP4-specific IgG binding to AQP4, when assembled into OAPs, greatly increases complement activation because of the multivalent binding characteristics of complement protein $C 1 \mathrm{Q}^{120}$. Binding of AQP4-specific IgG does not alter AQP4 water permeability, the plasma membrane AQP4-M1/AQP4-M23 isoform ratio or OAP assembly ${ }^{24}$. In cultured cells transfected with Aqp4, AQP4-specific IgG binding causes AQP4 internalization ${ }^{118}$, but this is unlikely to have a role in NMO because AQP4 internalization is not seen in primary astrocyte cultures or in the mouse brain ${ }^{121}$.

When injected intracerebrally in mice, AQP4-specific IgG binds to AQP4, producing the characteristic histolog-ical features of human NMO, including astrocyte damage, perivascular deposition of activated complement proteins, leukocyte infiltration, myelin loss 
and neuronal cell death ${ }^{122}$. The inflammatory cells associated with NMO are primarily granulocytes (neutrophils and eosinophils) and macrophages, with few lymphocytes, whereas MS lesions are devoid of granulocytes but rich in lymphocytes and macrophages. Current therapies for NMO target the immune response and/or the level of circulating AQP4-specific IgG, and include general immunosuppres-sion, plasma exchange and anti-B cell therapy ${ }^{111}$.

Although the discovery of AQP4-specific IgG has revolutionized our understanding of NMO pathogenesis (FIG. 5) and has suggested novel therapeutic strategies, as discussed below, major unanswered questions remain. Why are peripheral AQP4-expressing organs not damaged by AQP4-specific IgG, how does peripherally produced AQP4-specific IgG enter the CNS, why is there a predilection for the optic nerves and spinal cord and what causes AQP4-specific IgG-seronegative NMO? The reader is referred to recent reviews for further details on NMO pathogenesis mechanisms ${ }^{51,52,111}$.

\section{Brain tumours}

Astrocytomas are the most common primary brain tumours. They are histologically classified into grades I-IV depending on malignancy, with grade IV astrocytomas (glioblastoma multiforme or just glioblas-toma) being the most common. Even with extensive surgical debulking, radiotherapy and chemotherapy, the median survival time for individuals with glioblastoma is less than 1 year from diagnosis ${ }^{123}$. Glioblastoma cells are difficult to eradicate because they infiltrate extensively into the surrounding brain, precluding effective surgical excision. Following the initial observation of Saadoun et al. ${ }^{34}$ of strong AQP4 expression in astrocytomas, with the highest levels of this channel being found in glioblas-tomas, several studies have reported similar findings ${ }^{124,125}$. Glioblastomas sometimes also express AQP1 and AQP9 (REFS 45,126). The correlation between the level of AQP expression in tumour cells and the amount of tumour oedema, as revealed by MRI, has suggested the involvement of AQPs in tumour oedema ${ }^{127}$, although a more intriguing idea is that AQPs facilitate tumour cell migration through the ECS, thus facilitating the infiltration of such cells into the surrounding tissue ${ }^{128}$. The potential therapeutic implications of tumour cell AQP expression include the use of AQP inhibitors to reduce tumour cell infiltration and AQP4-targeted toxins to kill tumour cells.

\section{Aquaporin-based therapeutics}

There has been much speculation, but little progress, in the development of AQP-targeted therapeutics for nervous system disorders ${ }^{129,130}$. Phenotype data from knockout mice and basic physiological principles suggest the use of AQP4 water channel blockers to reduce brain oedema in stroke, trauma and other disorders associated with a primary cytotoxic response. There is also a good rationale for the development of AQP inhibitors to reduce the migration and hence local invasion of astrocytoma tumour cells and perhaps to reduce glial scarring and hence facilitate neuronal regeneration following stroke or trauma. AQP1 inhibitors may provide a non-narcotic approach to reduce nociception in certain types of pain. Other proposed applications of AQP modulators - including accelerating brain water clearance in vasogenic oedema, anti-epileptic action, anti-inflammatory action and others require further mechanistic understanding of AQP-dependent pathophysiology.

Limited progress has been made in AQP-targeted therapeutics. Sulfhydryl-reactive heavy metal ions, such as mercury and gold, inhibit water permeability by several AQPs ${ }^{131}$; however, they are not suitable for use in live cells because of their toxicity and generalized protein reactivity. There have been isolated reports that anti-epileptics ${ }^{132}$, carbonic anhydrase inhibitors ${ }^{133}, 5$-hydroxytryptamine agonists ${ }^{131}$, loop diuretics ${ }^{134,135}$, zinc ${ }^{136}$ and other molecules ${ }^{137}$ have water channel inhibition action, although subsequent re-evaluation 
did not confirm water channel inhibition ${ }^{138}$. The reasons for slow progress in AQP inhibitor discovery might include intrinsic poor 'druggability' of AQPs as targets for small molecules and challenges in developing and carrying out robust high-throughput screens.

One area of AQP therapeutics in which progress has been made is in NMO, which, as mentioned above, involves binding of pathogenic AQP4-specific autoanti-bodies to AQP4 on astrocytes, complement-dependent cytotoxicity and an inflammatory response. Biological and small-molecule therapeutics have been developed that block AQP4-specific IgG binding to AQP4 by targeting the extracellular surface of AQP4 (REFS 139,140). Of particular interest is aquaporumab, a high-affinity monoclonal AQP4-specific antibody that has been rendered non-pathogenic by mutation of its $\mathrm{Fc}$ region (BOX 2). Aquaporumab competes with pathogenic AQP4-specific IgG for binding to AQP4, reducing NMO pathology in ex vivo and in vivo NMO models ${ }^{139}$. Another approach involves IgG-selective enzymatic deglycosylation (BOX 2), which neutralizes AQP4-specific IgG pathogenicity and produces a therapeutic blocking antibody ${ }^{141}$.

\section{Box 2}

\section{Aquaporin 4 'blocking therapy' in neuromyelitis optica}

An initiating step in producing astrocyte damage and an inflammatory reaction in neuromyelitis optica (NMO) is the binding of the aquaporin 4 (AQP4)-specific autoantibody, immunoglobulin $\mathrm{G}(\mathrm{IgG})$, to AQP4 on the plasma membrane of astrocytes. The rationale of 'blocking therapies' under development for NMO is to prevent AQP4specific IgG binding to AQP4. In one form of blocking therapy, a non-pathogenic, highaffinity AQP4-specific antibody (aquaporumab) was engineered. The figure (left panel) shows that an IgG1 antibody is substantially larger than an AQP4 tetramer, and this sterically limits the number of antibodies that can bind to such tetramers. A high-affinity $\mathrm{AQP} 4$-specific IgG antibody was identified by screening monoclonal antibodies derived from clonally expanded plasma blast populations from the cerebrospinal fluid of patients with $\mathrm{NMO}^{160}$. The antibody Fc region was mutated to abolish its complement-dependent and cell-dependent cytotoxicity functions ${ }^{139}$. The figure (right panel) shows the antibody structure, with heavy $\left(\mathrm{V}_{\mathrm{H}}\right)$ and light $\left(\mathrm{V}_{\mathrm{L}}\right)$ chain variable regions, light chain constant region $\left(\mathrm{C}_{\mathrm{L}}\right)$, and heavy chain constant regions $\left(\mathrm{C}_{\mathrm{H}} 1-\mathrm{C}_{\mathrm{H}} 3\right)$. The mutations $\mathrm{L} 234 \mathrm{~A}$ and L235A in Fc abolished antibody cytotoxicity effector functions. Because of the large size of aquaporumab compared with AQP4, aquaporumab competes with the binding of pathogenic, polyclonal AQP4-specific antibodies in NMO, preventing astrocyte cytotoxicity and downstream inflammation and demyelination, as demonstrated in $e x$ vivo and in vivo mouse models of NMO. An alternative approach to aquaporumab involves enzymatic deglycosylation of a patient's own AQP4-specific IgG to render it non-pathogenic ${ }^{141}$. Endoglycosidase $\mathrm{S}$ is a bacterial enzyme that selectively cleaves glycans on residue N297 of IgG heavy chains (shown in the right panel of the figure). This enzyme was shown to render patient AQP4-specific IgG non-pathogenic without affecting AQP4 binding, thus converting a pathogenic antibody to a therapeutic blocking antibody. A third approach involves small drug-like molecules, which are identified by high-throughput screening, that bind to the extracellular surface of AQP4 and compete with patient AQP4-specific $\operatorname{IgG}^{140}$. 


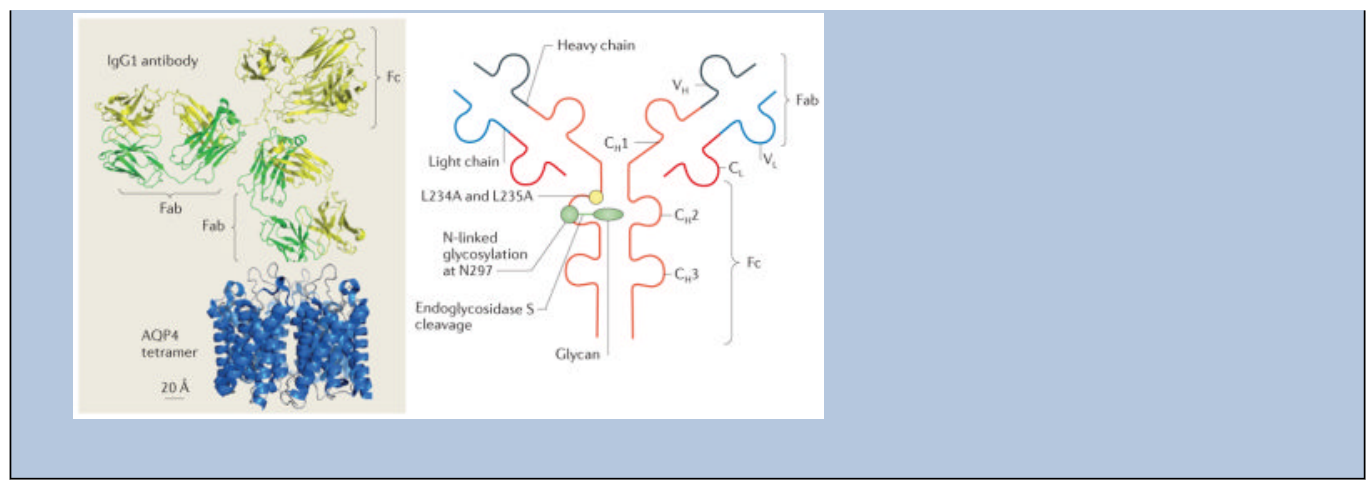

\section{Conclusions}

The field of AQP neuroscientific research has advanced remarkably in the past decade. Important discoveries that could not have been predicted from the known function of AQPs as water channels include the discovery of AQP4-specific antibodies and their role in inflammatory demyelination, and the role for AQPs in cell migration. Despite these advances, there remain many questions about the cellular mechanisms of AQP functions in the nervous system and areas for further investigation. AQP-selective inhibitors are badly needed as research tools to determine whether the various phenotypes that are seen in AQP knockout mice are bona fide, isolated effects of loss of AQP function rather than secondary effects of gene knockout. For example, it is unclear whether loss of AQP4 water transport function is directly responsible for defective neuroexcitation and brain water clearance in knockout mice, or whether these phenotypes are secondary to an expanded ECS or changes in the expression of non- $A q p$ genes. The possible functions of AQPs in the peripheral and enteric nervous systems, and in associated diseases, also need to be investigated. Further study is also warranted into the possible involvement of AQP1 and AQP3 in intervertebral disc hydration and spinal mechanics, and in clinical disc dehydration and degeneration.

Notwithstanding these gaps in our understanding of the functions and cellular mechanisms of AQP involvement in nervous system function, there are compelling opportunities to translate bench neuroscience into therapeutics, particularly in the areas of brain tumours, neuroinflammation, cerebral and spinal cord oedema and, potentially, pain, epilepsy and stroke. It is unlikely that $A Q P 4$ genetic variability has a major role in human diseases, as $A Q P 4$ polymorphisms do not appear to have a causative role in $\mathrm{NMO}^{142}$, brain oedema after middle cerebral artery stroke ${ }^{143}$ and temporal lobe epilepsy ${ }^{144}$. Continued advances are anticipated in our understanding of the cellular mechanisms of AQP function, as well as in AQP-targeted small-molecule therapeutics and biologics for the treatment of neurological disorders.

\section{Acknowledgments}

Our research is funded by the US National Institutes of Health and the Guthy-Jackson Charitable Foundation. We thank S. Saadoun for providing helpful criticism of the manuscript.

\section{Glossary}

\section{a-syntrophin}

Agrin
An intracellular protein that may form a complex with aquaporin 4

A proteoglycan attached to extracellular matrix that may anchor aquaporin 4 in the membrane 
Glial-limiting membrane

Circumventricular organs

Choroid plexus

Tanycytes

Ruffini mechanoreceptors

Müller cells

Claudius cells

Hensen cells

Inner sulcus cells

Cytotoxic oedema

Vasogenic oedema

Ependyma

Kaolin

Lamellipodia

Glioblastoma multiforme

C5b-C9 complexes

Plasma blast
This is the interface between the brain and the surrounding cerebrospinal fluid, and comprises astrocyte processes

These are regions of the brain near ventricles that lack the blood-brain barrier

An intraventricular epithelial structure that secretes cerebrospinal fluid

These are elongated cells that project from the third ventricle to the hypothalamus

These are skin mechanoreceptors

These are aquaporin 4-expressing retinal glial cells

These are supporting cells (non-excitable cells) in the inner ear

These are supporting cells (non-excitable cells) in the inner ear

These are supporting cells (non-excitable cells) in the inner ear

This is the intracellular accumulation of excess water (cellswelling oedema)

This is the interstitial accumulation of excess brain water (leaky-vessel oedema)

A membrane of epithelial cells lining the ventricles

This is aluminium silicate that causes obstructive hydrocephalus when injected into the cisterna magna of rodents

Projections at the front end of a migrating cell

This is a highly infiltrative, malignant tumour of astrocytes

Cell plasma membrane pores composed of the complement proteins C5b, C6, C7, C8 and C9. Deposition of enough pores causes cell lysis

Upon activation by $\mathrm{T}$ helper cells, B cells differentiate into plasma cells that secrete high levels of antibody. Plasma blasts are the most immature plasma cells

\section{References}

1. Preston GM, Agre P. Isolation of the cDNA for erythrocyte integral membrane protein of 28 kilodaltons: member of an ancient channel family. Proc Natl Acad Sci USA. 1991; 88:1111011114. This paper reports the discovery of water channel proteins. [PubMed: 1722319]

2. Carbrey JM, Agre P. Discovery of the aquaporins and development of the field. Handb Exp Pharmacol. 2009; 190:3-28. [PubMed: 19096770]

3. Verkman AS. Aquaporins in clinical medicine. Annu Rev Med. 2012; 63:303-316. [PubMed: 22248325] 
4. Soveral G, Prista C, Moura TF, Loureiro-Dias MC. Yeast water channels: an overview of orthodox aquaporins. Biol Cell. 2010; 103:35-54. [PubMed: 21143194]

5. Tanghe A, Van Dijck P, Thevelein JM. Why do microorganisms have aquaporins? Trends Microbiol. 2006; 14:78-85. [PubMed: 16406529]

6. Wu B, Beitz E. Aquaporins with selectivity for unconventional permeants. Cell Mol Life Sci. 2007; 64:2413-2421. [PubMed: 17571212]

7. Rojek A, Praetorius J, Frokiaer J, Nielsen S, Fenton RA. A current view of the mammalian aquaglyceroporins. Annu Rev Physiol. 2008; 70:301-327. [PubMed: 17961083]

8. Herrera M, Garvin JL. Aquaporins as gas channels. Pflugers Arch. 2011; 462:623-630. [PubMed: 21809007]

9. Geers C, Gros G. Carbon dioxide transport and carbonic anhydrase in blood and muscle. Physiol Rev. 2000; 80:681-715. [PubMed: 10747205]

10. Walz T, Fujiyoshi Y, Engel A. The AQP structure and functional implications. Handb Exp Pharmacol. 2009; 190:31-56. [PubMed: 19096771]

11. Ho JD, et al. Crystal structure of human aquaporin 4 at $1.8 \mathrm{~A}$ and its mechanism of conductance. Proc Natl Acad Sci USA. 2009; 106:7437-7442. [PubMed: 19383790]

12. Cui Y, Bastien DA. Water transport in human aquaporin-4: molecular dynamics (MD) simulations. Biochem Biophys Res Commun. 2011; 412:654-659. [PubMed: 21856282]

13. Hub JS, Grubmuller H, de Groot BL. Dynamics and energetics of permeation through aquaporins. What do we learn from molecular dynamics simulations? Handb Exp Pharmacol. 2009; 190:5776. [PubMed: 19096772]

14. Yang B, Brown D, Verkman AS. The mercurial insensitive water channel (AQP-4) forms orthogonal arrays in stably transfected Chinese hamster ovary cells. J Biol Chem. 1996; 271:45774580. [PubMed: 8617713]

15. Verbavatz JM, Ma T, Gobin R, Verkman AS. Absence of orthogonal arrays in kidney, brain and muscle from transgenic knockout mice lacking water channel aquaporin-4. J Cell Sci. 1997; 110:2855-2860. [PubMed: 9427293]

16. Wolburg H, Wolburg-Buchholz K, Fallier-Becker P, Noell S, Mack AF. Structure and functions of aquaporin-4-based orthogonal arrays of particles. Int Rev Cell Mol Biol. 2011; 287:1-41. [PubMed: 21414585]

17. Rash JE, Yasumura T, Hudson CS, Agre P, Nielsen S. Direct immunogold labeling of aquaporin-4 in square arrays of astrocyte and ependymocyte plasma membranes in rat brain and spinal cord. Proc Natl Acad Sci USA. 1998; 95:11981-11986. This paper provides one of the earliest descriptions of AQP4 expression in the brain. [PubMed: 9751776]

18. Rossi A, Moritz TJ, Ratelade J, Verkman AS. Super-resolution imaging of aquaporin-4 orthogonal arrays of particles in cell membranes. J Cell Sci. 2012; 125:4405-4412. [PubMed: 22718347]

19. Neely JD, Christensen BM, Nielsen S, Agre P. Heterotetrameric composition of aquaporin-4 water channels. Biochemistry. 1999; 38:11156-11163. [PubMed: 10460172]

20. Jin BJ, Rossi A, Verkman AS. Model of aquaporin-4 supramolecular assembly in orthogonal arrays based on heterotetrameric association of M1-M23 isoforms. Biophys J. 2011; 100:29362945. [PubMed: 21689527]

21. Crane JM, Verkman AS. Determinants of aquaporin-4 assembly in orthogonal arrays revealed by live-cell single-molecule fluorescence imaging. J Cell Sci. 2009; 122:813-821. [PubMed: 19240114]

22. Fenton RA, et al. Differential water permeability and regulation of three aquaporin 4 isoforms. Cell Mol Life Sci. 2010; 67:829-840. [PubMed: 20013023]

23. Hiroaki Y, et al. Implications of the aquaporin-4 structure on array formation and cell adhesion. J Mol Biol. 2006; 355:628-639. [PubMed: 16325200]

24. Rossi A, Ratelade J, Papadopoulos MC, Bennett JL, Verkman AS. Neuromyelitis optica IgG does not alter aquaporin-4 water permeability, plasma membrane M1/M23 isoform content, or supramolecular assembly. Glia. 2013; 60:2027-2039. [PubMed: 22987455]

25. Zhang H, Verkman AS. Evidence against involvement of aquaporin-4 in cell-cell adhesion. J Mol Biol. 2008; 382:1136-1143. [PubMed: 18708067] 
26. Furman CS, et al. Aquaporin-4 square array assembly: opposing actions of M1 and M23 isoforms. Proc Natl Acad Sci USA. 2003; 100:13609-13614. [PubMed: 14597700]

27. Papadopoulos MC, Manley GT, Krishna S, Verkman AS. Aquaporin-4 facilitates reabsorption of excess fluid in vasogenic brain edema. FASEB J. 2004; 18:1291-1293. [PubMed: 15208268]

28. Oshio K, et al. Expression of aquaporin water channels in mouse spinal cord. Neuroscience. 2004; 127:685-693. [PubMed: 15283967]

29. Nagelhus EA, et al. Aquaporin-4 water channel protein in the rat retina and optic nerve: polarized expression in Müller cells and fibrous astrocytes. J Neurosci. 1998; 18:2506-2519. [PubMed: 9502811]

30. Nielsen S, et al. Specialized membrane domains for water transport in glial cells: high-resolution immunogold cytochemistry of aquaporin-4 in rat brain. J Neurosci. 1997; 17:171-180. [PubMed: 8987746]

31. Neely JD, et al. Syntrophin-dependent expression and localization of Aquaporin-4 water channel protein. Proc Natl Acad Sci USA. 2001; 98:14108-14113. [PubMed: 11717465]

32. Noell S, et al. Effects of agrin on the expression and distribution of the water channel protein aquaporin-4 and volume regulation in cultured astrocytes. Eur J Neurosci. 2007; 26:2109-2118. [PubMed: 17927773]

33. Wolburg H, Noell S, Wolburg-Buchholz K, Mack A, Fallier-Becker P. Agrin, aquaporin-4, and astrocyte polarity as an important feature of the blood-brain barrier. Neuroscientist. 2009; 15:180193. [PubMed: 19307424]

34. Saadoun S, Papadopoulos MC, Davies DC, Krishna S, Bell BA. Aquaporin-4 expression is increased in oedematous human brain tumours. J Neurol Neurosurg Psychiatry. 2002; 72:262-265. This is the first demonstration of increased AQP expression in tumours. [PubMed: 11796780]

35. Solenov E, Watanabe H, Manley GT, Verkman AS. Sevenfold-reduced osmotic water permeability in primary astrocyte cultures from AQP-4-deficient mice, measured by a fluorescence quenching method. Am J Physiol Cell Physiol. 2004; 286:C426-C432. [PubMed: 14576087]

36. Nicchia GP, et al. Aquaporin-4-containing astrocytes sustain a temperature- and mercuryinsensitive swelling in vitro. Glia. 2000; 31:29-38. [PubMed: 10816604]

37. Hsu MS, et al. Laminar-specific and developmental expression of aquaporin-4 in the mouse hippocampus. Neuroscience. 2011; 178:21-32. [PubMed: 21256195]

38. Binder DK, et al. Increased seizure duration and slowed potassium kinetics in mice lacking aquaporin-4 water channels. Glia. 2006; 53:631-636. [PubMed: 16470808]

39. Padmawar P, Yao X, Bloch O, Manley GT, Verkman AS. $\mathrm{K}^{+}$waves in brain cortex visualized using a long-wavelength $\mathrm{K}^{+}$-sensing fluorescent indicator. Nature Methods. 2005; 2:825-827. [PubMed: 16278651]

40. Amiry-Moghaddam $\mathrm{M}$, et al. Delayed $\mathrm{K}^{+}$clearance associated with aquaporin- 4 mislocalization: phenotypic defects in brains of a-syntrophin-null mice. Proc Natl Acad Sci USA. 2003; 100:13615-13620. [PubMed: 14597704]

41. Nielsen S, Smith BL, Christensen EI, Agre P. Distribution of the aquaporin CHIP in secretory and resorptive epithelia and capillary endothelia. Proc Natl Acad Sci USA. 1993; 90:7275-7279. [PubMed: 8346245]

42. Oshio K, Watanabe H, Song Y, Verkman AS, Manley GT. Reduced cerebrospinal fluid production and intracranial pressure in mice lacking choroid plexus water channel Aquaporin-1. FASEB J. 2005; 19:76-78. [PubMed: 15533949]

43. Wilson AJ, Carati CJ, Gannon BJ, Haberberger R, Chataway TK. Aquaporin-1 in blood vessels of rat circumventricular organs. Cell Tissue Res. 2010; 340:159-168. [PubMed: 20177708]

44. Dolman D, Drndarski S, Abbott NJ, Rattray M. Induction of aquaporin 1 but not aquaporin 4 messenger RNA in rat primary brain microvessel endothelial cells in culture. J Neurochem. 2005; 93:825-833. [PubMed: 15857386]

45. Saadoun S, Papadopoulos MC, Davies DC, Bell BA, Krishna S. Increased aquaporin 1 water channel expression in human brain tumours. Br J Cancer. 2002; 87:621-623. [PubMed: 12237771]

46. Badaut J, et al. Distribution of Aquaporin 9 in the adult rat brain: preferential expression in catecholaminergic neurons and in glial cells. Neuroscience. 2004; 128:27-38. [PubMed: 15450351] 
47. Shields SD, Mazario J, Skinner K, Basbaum AI. Anatomical and functional analysis of aquaporin 1, a water channel in primary afferent neurons. Pain. 2007; 131:8-20. [PubMed: 17257750]

48. Hofman P, Hoyng P, vanderWerf F, Vrensen GF, Schlingemann RO. Lack of blood-brain barrier properties in microvessels of the prelaminar optic nerve head. Invest Ophthalmol Vis Sci. 2001; 42:895-901. [PubMed: 11274064]

49. Venero JL, et al. Detailed localization of aquaporin-4 messenger RNA in the CNS: preferential expression in periventricular organs. Neuroscience. 1999; 94:239-250. [PubMed: 10613514]

50. Ma T, Gao H, Fang X, Yang H. Water channel proteins in the peripheral nervous system in health and disease. Mol Aspects Med. 2012; 33:605-611. [PubMed: 22476045]

51. Papadopoulos MC, Verkman AS. Aquaporin 4 and neuromyelitis optica. Lancet Neurol. 2012; 11:535-544. [PubMed: 22608667]

52. Jarius S, Wildemann B. AQP4 antibodies in neuromyelitis optica: diagnostic and pathogenetic relevance. Nature Rev Neurol. 2010; 6:383-392. [PubMed: 20639914]

53. Oshio K, Watanabe H, Yan D, Verkman AS, Manley GT. Impaired pain sensation in mice lacking Aquaporin-1 water channels. Biochem Biophys Res Commun. 2006; 341:1022-1028. [PubMed: 16476579]

54. Gao H, et al. Localization of aquaporin-1 water channel in glial cells of the human peripheral nervous system. Glia. 2006; 53:783-787. [PubMed: 16534779]

55. Nandasena BG, et al. Immunolocalization of aquaporin-1 in the mechanoreceptive Ruffini endings in the periodontal ligament. Brain Res. 2007; 1157:32-40. [PubMed: 17553469]

56. Li J, Patil RV, Verkman AS. Mildly abnormal retinal function in transgenic mice without Müller cell aquaporin-4 water channels. Invest Ophthalmol Vis Sci. 2002; 43:573-579. [PubMed: 11818406]

57. Lu DC, Zhang H, Zador Z, Verkman AS. Impaired olfaction in mice lacking aquaporin-4 water channels. FASEB J. 2008; 22:3216-3223. [PubMed: 18511552]

58. Li J, Verkman AS. Impaired hearing in mice lacking aquaporin-4 water channels. J Biol Chem. 2001; 276:31233-31237. This is the first report showing that AQP4 has a role in sensory perception. [PubMed: 11406631]

59. Verkman AS, Ruiz-Ederra J, Levin MH. Functions of aquaporins in the eye. Prog Retin Eye Res. 2008; 27:420-433. [PubMed: 18501660]

60. Nagahama M, Ma N, Semba R, Naruse S. Aquaporin 1 immunoreactive enteric neurons in the rat ileum. Neurosci Lett. 2006; 395:206-210. [PubMed: 16309835]

61. Arciszewski MB. Neurochemical properties of aquaporin 1-expressing sensory neurons from the ovine trigeminal ganglion. Anat Histol Embryol. 2012; 41:184-189. [PubMed: 22150518]

62. Thi MM, Spray DC, Hanani M. Aquaporin-4 water channels in enteric neurons. J Neurosci Res. 2008; 86:448-456. [PubMed: 17893913]

63. Ishihara E, et al. Neuropathological alteration of aquaporin 1 immunoreactive enteric neurons in the streptozotocin-induced diabetic rats. Auton Neurosci. 2008; 138:31-40. [PubMed: 17936693]

64. Richardson SM, Knowles R, Marples D, Hoyland JA, Mobasheri A. Aquaporin expression in the human intervertebral disc. J Mol Histol. 2008; 39:303-309. [PubMed: 18247144]

65. Aharon R, Bar-Shavit Z. Involvement of aquaporin 9 in osteoclast differentiation. J Biol Chem. 2006; 281:19305-19309. [PubMed: 16698796]

66. Bass NH, Hess HH, Pope A, Thalheimer C. Quantitative cytoarchitectonic distribution of neurons, glia, and DNa in rat cerebral cortex. J Comp Neurol. 1971; 143:481-490. [PubMed: 4945394]

67. Arcienega II, Brunet JF, Bloch J, Badaut J. Cell locations for AQP1, AQP4 and 9 in the nonhuman primate brain. Neuroscience. 2010; 167:1103-1114. [PubMed: 20226845]

68. Fischbarg J, et al. Glucose transporters serve as water channels. Proc Natl Acad Sci USA. 1990; 87:3244-3247. [PubMed: 2326282]

69. Iwamoto M, Oiki S. Counting ion and water molecules in a streaming file through the open-filter structure of the K channel. J Neurosci. 2011; 31:12180-12188. [PubMed: 21865461]

70. Papadopoulos MC, Verkman AS. Aquaporin-4 gene disruption in mice reduces brain swelling and mortality in pneumococcal meningitis. J Biol Chem. 2005; 280:13906-13912. [PubMed: 15695511] 
71. Badaut $\mathrm{J}$, et al. Brain water mobility decreases after astrocytic aquaporin-4 inhibition using RNA interference. J Cereb Blood Flow Metab. 2011; 31:819-831. [PubMed: 20877385]

72. Haj-Yasein NN, et al. Glial-conditional deletion of aquaporin-4 (Aqp4) reduces blood-brain water uptake and confers barrier function on perivascular astrocyte endfeet. Proc Natl Acad Sci USA. 2011; 108:17815-17820. [PubMed: 21990350]

73. Marmarou A. A review of progress in understanding the pathophysiology and treatment of brain edema. Neurosurg Focus. 2007; 22:e1.

74. Papadopoulos MC, Verkman AS. Aquaporin-4 and brain edema. Pediatr Nephrol. 2007; 22:778784. [PubMed: 17347837]

75. Zador Z, Stiver S, Wang V, Manley GT. Role of aquaporin-4 in cerebral edema and stroke. Handb Exp Pharmacol. 2009; 190:159-170. [PubMed: 19096776]

76. Sun MC, Honey CR, Berk C, Wong NL, Tsui JK. Regulation of aquaporin-4 in a traumatic brain injury model in rats. J Neurosurg. 2003; 98:565-569. [PubMed: 12650429]

77. Saadoun S, Papadopoulos MC, Krishna S. Water transport becomes uncoupled from $\mathrm{K}^{+}$siphoning in brain contusion, bacterial meningitis, and brain tumours: immunohistochemical case review. $\mathbf{J}$ Clin Pathol. 2003; 56:972-975. [PubMed: 14645363]

78. Filippidis AS, Kalani MY, Rekate HL. Hydrocephalus and aquaporins: the role of aquaporin-4. Acta Neurochir Suppl. 2012; 113:55-58. [PubMed: 22116424]

79. Manley GT, et al. Aquaporin-4 deletion in mice reduces brain edema after acute water intoxication and ischemic stroke. Nature Med. 2000; 6:159-163. This study provides the first direct evidence that AQP4 plays a part in brain oedema. [PubMed: 10655103]

80. Amiry-Moghaddam M, et al. An a-syntrophin-dependent pool of AQP4 in astroglial end-feet confers bidirectional water flow between blood and brain. Proc Natl Acad Sci USA. 2003; 100:2106-2111. [PubMed: 12578959]

81. Vajda Z, et al. Delayed onset of brain edema and mislocalization of aquaporin-4 in dystrophin-null transgenic mice. Proc Natl Acad Sci USA. 2002; 99:13131-13136. [PubMed: 12232046]

82. Nico B, et al. Severe alterations of endothelial and glial cells in the blood-brain barrier of dystrophic mdx mice. Glia. 2003; 42:235-251. [PubMed: 12673830]

83. Saadoun S, Bell BA, Verkman AS, Papadopoulos MC. Greatly improved neurological outcome after spinal cord compression injury in AQP4-deficient mice. Brain. 2008; 131:1087-1098. [PubMed: 18267965]

84. Thrane AS, et al. Critical role of aquaporin-4 (AQP4) in astrocytic $\mathrm{Ca}^{2+}$ signaling events elicited by cerebral edema. Proc Natl Acad Sci USA. 2011; 108:846-851. [PubMed: 21187412]

85. Yang B, Zador Z, Verkman AS. Glial cell aquaporin-4 overexpression in transgenic mice accelerates cytotoxic brain swelling. J Biol Chem. 2008; 283:15280-15286. [PubMed: 18375385]

86. Bloch O, Papadopoulos MC, Manley GT, Verkman AS. Aquaporin-4 gene deletion in mice increases focal edema associated with staphylococcal brain abscess. J Neurochem. 2005; 95:254262. [PubMed: 16181429]

87. Tait MJ, Saadoun S, Bell BA, Verkman AS, Papadopoulos MC. Increased brain edema in aqp4 null mice in an experimental model of subarachnoid hemorrhage. Neuroscience. 2010; 167:60-67. [PubMed: 20132873]

88. Lee DJ, et al. Aquaporin-4-dependent edema clearance following status epilepticus. Epilepsy Res. 2012; 98:264-268. [PubMed: 21996149]

89. Kimura A, et al. Protective role of aquaporin- 4 water channels after contusion spinal cord injury. Ann Neurol. 2010; 67:794-801. [PubMed: 20517941]

90. Iliff JJ, et al. A paravascular pathway facilitates CSF flow through the brain parenchyma and the clearance of interstitial solutes, including amyloid $\beta$. Sci Transl Med. 2012; 4:147ra111.

91. Feng X, et al. Sporadic obstructive hydrocephalus in Aqp4 null mice. J Neurosci Res. 2009; 87:1150-1155. [PubMed: 18951529]

92. Bloch O, Auguste KI, Manley GT, Verkman AS. Accelerated progression of kaolin-induced hydrocephalus in aquaporin-4-deficient mice. J Cereb Blood Flow Metab. 2006; 26:1527-1537. [PubMed: 16552421] 
93. Loitto VM, Magnusson KE. $\mathrm{Hg}^{2+}$ and small-sized polyethylene glycols have inverse effects on membrane permeability, while both impair neutrophil cell motility. Biochem Biophys Res Commun. 2004; 316:370-378. [PubMed: 15020227]

94. Saadoun S, Papadopoulos MC, Hara-Chikuma M, Verkman AS. Impairment of angiogenesis and cell migration by targeted aquaporin-1 gene disruption. Nature. 2005; 434:786-792. This study demonstrates that AQPs facilitate cell migration. [PubMed: 15815633]

95. Papadopoulos MC, Saadoun S, Verkman AS. Aquaporins and cell migration. Pflugers Arch. 2008; 456:693-700. [PubMed: 17968585]

96. Hu J, Verkman AS. Increased migration and metastatic potential of tumor cells expressing aquaporin water channels. FASEB J. 2006; 20:1892-1894. [PubMed: 16818469]

97. Saadoun S, et al. Involvement of aquaporin-4 in astroglial cell migration and glial scar formation. J Cell Sci. 2005; 118:5691-5698. [PubMed: 16303850]

98. Auguste KI, et al. Greatly impaired migration of implanted aquaporin-4-deficient astroglial cells in mouse brain toward a site of injury. FASEB J. 2007; 21:108-116. [PubMed: 17135365]

99. Charras GT, Yarrow JC, Horton MA, Mahadevan L, Mitchison TJ. Non-equilibration of hydrostatic pressure in blebbing cells. Nature. 2005; 435:365-369. [PubMed: 15902261]

100. Rabinovitch M, DeStefano MJ. Spontaneous migration of normal human polymorphonuclear neutrophils under agarose: enhancement by media of lowered $\mathrm{pH}$ or osmolality. $\mathbf{J}$

Reticuloendothel Soc. 1981; 29:329-339. [PubMed: 7241408]

101. Nicchia GP, et al. New possible roles for aquaporin-4 in astrocytes: cell cytoskeleton and functional relationship with connexin43. FASEB J. 2005; 19:1674-1676. [PubMed: 16103109]

102. Binder DK, Oshio K, Ma T, Verkman AS, Manley GT. Increased seizure threshold in mice lacking aquaporin-4 water channels. Neuroreport. 2004; 15:259-262. [PubMed: 15076748]

103. Lee DJ, Hsu MS, Seldin MM, Arellano JL, Binder DK. Decreased expression of the glial water channel aquaporin-4 in the intrahippocampal kainic acid model of epileptogenesis. Exp Neurol. 2012; 235:246-255. [PubMed: 22361023]

104. Binder DK, Nagelhus EA, Ottersen OP. Aquaporin-4 and epilepsy. Glia. 2012; 60:1203-1214. [PubMed: 22378467]

105. Strohschein $\mathrm{S}$, et al. Impact of aquaporin-4 channels on $\mathrm{K}^{+}$buffering and gap junction coupling in the hippocampus. Glia. 2011; 59:973-980. [PubMed: 21446052]

106. Nicholson C, Sykova E. Extracellular space structure revealed by diffusion analysis. Trends Neurosci. 1998; 21:207-215. [PubMed: 9610885]

107. Nagelhus EA, et al. Immunogold evidence suggests that coupling of $\mathrm{K}^{+}$siphoning and water transport in rat retinal Müller cells is mediated by a coenrichment of Kir4.1 and AQP4 in specific membrane domains. Glia. 1999; 26:47-54. [PubMed: 10088671]

108. Ruiz-Ederra J, Zhang H, Verkman AS. Evidence against functional interaction between aquaporin-4 water channels and Kir4.1 potassium channels in retinal Müller cells. J Biol Chem. 2007; 282:21866-21872. [PubMed: 17525153]

109. Jin BJ, Zhang B, Binder DK, Verkman AS. Aquaporin-4-dependent $\mathrm{K}^{+}$and water transport modeled in brain extracellular space following neuroexcitation. J Gen Physiol. 2013; 141:261272. [PubMed: 23359285]

110. Zhang H, Verkman AS. Aquaporin-1 tunes pain ${ }^{+}$channels in perception by interaction with $\mathrm{Na}_{\mathrm{v}} 1.8 \mathrm{Na}$ dorsal root ganglion neurons. J Biol Chem. 2010; 285:5896-5906. [PubMed: 20018876]

111. Wingerchuk DM, Lennon VA, Lucchinetti CF, Pittock SJ, Weinshenker BG. The spectrum of neuromyelitis optica. Lancet Neurol. 2007; 6:805-815. [PubMed: 17706564]

112. Lennon VA, et al. A serum autoantibody marker of neuromyelitis optica: distinction from multiple sclerosis. Lancet. 2004; 364:2106-2112. [PubMed: 15589308]

113. Lennon VA, Kryzer TJ, Pittock SJ, Verkman AS, Hinson SR. IgG marker of optic-spinal multiple sclerosis binds to the aquaporin-4 water channel. J Exp Med. 2005; 202:473-477. This study identifies AQP4 as the target of NMO autoantibodies. [PubMed: 16087714]

114. Pisani F, et al. Identification of two major conformational aquaporin-4 epitopes for neuromyelitis optica autoantibody binding. J Biol Chem. 2011; 286:9216-9224. [PubMed: 21212277] 
115. Tani $\mathrm{T}$, et al. Identification of binding sites for anti-aquaporin 4 antibodies in patients with neuromyelitis optica. J Neuroimmunol. 2009; 211:110-113. [PubMed: 19410301]

116. Yu X, et al. Identification of peptide targets in neuromyelitis optica. J Neuroimmunol. 2011; 236:65-71. [PubMed: 21621279]

117. Nicchia GP, et al. Aquaporin-4 orthogonal arrays of particles are the target for neuromyelitis optica autoantibodies. Glia. 2009; 57:1363-1373. [PubMed: 19229993]

118. Hinson SR, et al. Molecular outcomes of neuromyelitis optica (NMO)-IgG binding to aquaporin-4 in astrocytes. Proc Natl Acad Sci USA. 2012; 109:1245-1250. [PubMed: 22128336]

119. Crane JM, et al. Binding affinity and specificity of neuromyelitis optica autoantibodies to aquaporin-4 M1/M23 isoforms and orthogonal arrays. J Biol Chem. 2011; 286:16516-16524. [PubMed: 21454592]

120. Phuan PW, Ratelade J, Rossi A, Tradtrantip L, Verkman AS. Complement-dependent cytotoxicity in neuromyelitis optica requires aquaporin-4 protein assembly in orthogonal arrays. J Biol Chem. 2012; 287:13829-13839. [PubMed: 22393049]

121. Ratelade J, Bennett JL, Verkman AS. Evidence against cellular internalization in vivo of NMO$\mathrm{IgG}$, aquaporin-4, and excitatory amino acid transporter 2 in neuromyelitis optica. J Biol Chem. 2011; 286:45156-45164. [PubMed: 22069320]

122. Saadoun $S$, et al. Intra-cerebral injection of neuromyelitis optica immunoglobulin $G$ and human complement produces neuromyelitis optica lesions in mice. Brain. 2010; 133:349-361. [PubMed: 20047900]

123. Johnson DR, O'Neill BP. Glioblastoma survival in the United States before and during the temozolomide era. J Neurooncol. 2012; 107:359-364. [PubMed: 22045118]

124. Ikota H, Kinjo S, Yokoo H, Nakazato Y. Systematic immunohistochemical profiling of 378 brain tumors with 37 antibodies using tissue microarray technology. Acta Neuropathol. 2006; 111:475-482. [PubMed: 16598485]

125. Warth A, et al. Expression pattern of the water channel aquaporin-4 in human gliomas is associated with blood-brain barrier disturbance but not with patient survival. J Neurosci Res. 2007; 85:1336-1346. [PubMed: 17335082]

126. Badaut J. Aquaglyceroporin 9 in brain pathologies. Neuroscience. 2010; 168:1047-1057. [PubMed: 19850108]

127. Nico B, et al. Aquaporin-4 contributes to the resolution of peritumoural brain oedema in human glioblastoma multiforme after combined chemotherapy and radiotherapy. Eur J Cancer. 2009; 45:3315-3325. [PubMed: 19836227]

128. Verkman AS, Hara-Chikuma M, Papadopoulos MC. Aquaporins — new players in cancer biology. J Mol Med. 2008; 86:523-529. [PubMed: 18311471]

129. Frigeri A, Nicchia GP, Svelto M. Aquaporins as targets for drug discovery. Curr Pharm Des. 2007; 13:2421-2427. [PubMed: 17692010]

130. Yool AJ, Brown EA, Flynn GA. Roles for novel pharmacological blockers of aquaporins in the treatment of brain oedema and cancer. Clin Exp Pharmacol Physiol. 2010; 37:403-409. [PubMed: 19566827]

131. Niemietz CM, Tyerman SD. New potent inhibitors of aquaporins: silver and gold compounds inhibit aquaporins of plant and human origin. FEBS Lett. 2002; 531:443-447. [PubMed: 12435590]

132. Huber VJ, Tsujita M, Kwee IL, Nakada T. Inhibition of aquaporin 4 by antiepileptic drugs. Bioorg Med Chem. 2009; 17:418-424. [PubMed: 18178093]

133. Huber VJ, Tsujita M, Yamazaki M, Sakimura K, Nakada T. Identification of arylsulfonamides as Aquaporin 4 inhibitors. Bioorg Med Chem Lett. 2007; 17:1270-1273. [PubMed: 17178220]

134. Migliati E, et al. Inhibition of aquaporin-1 and aquaporin- 4 water permeability by a derivative of the loop diuretic bumetanide acting at an internal pore-occluding binding site. Mol Pharmacol. 2009; 76:105-112. [PubMed: 19403703]

135. Ozu M, Dorr RA, Teresa Politi M, Parisi M, Toriano R. Water flux through human aquaporin 1: inhibition by intracellular furosemide and maximal response with high osmotic gradients. Eur Biophys J. 2011; 40:737-746. [PubMed: 21373963] 
136. Yukutake Y, Hirano Y, Suematsu M, Yasui M. Rapid and reversible inhibition of aquaporin-4 by zinc. Biochemistry. 2009; 48:12059-12061. [PubMed: 19928950]

137. Mola MG, Nicchia GP, Svelto M, Spray DC, Frigeri A. Automated cell-based assay for screening of aquaporin inhibitors. Anal Chem. 2009; 81:8219-8229. [PubMed: 19705854]

138. Yang B, Zhang H, Verkman AS. Lack of aquaporin-4 water transport inhibition by antiepileptics and arylsulfonamides. Bioorg Med Chem. 2008; 16:7489-7493. [PubMed: 18572411]

139. Tradtrantip L, et al. Anti-aquaporin-4 monoclonal antibody blocker therapy for neuromyelitis optica. Ann Neurol. 2012; 71:314-322. [PubMed: 22271321]

140. Tradtrantip L, et al. Small-molecule inhibitors of NMO-IgG binding to aquaporin-4 reduce astrocyte cytotoxicity in neuromyelitis optica. FASEB J. 2012; 26:2197-2208. [PubMed: 22319008]

141. Tradtrantip L, Ratelade J, Zhang H, Verkman AS. Enzymatic deglycosylation converts pathogenic neuromyelitis optica anti-aquaporin-4 IgG into therapeutic antibody. Ann Neurol. 2013; 73:77-85. [PubMed: 23055279]

142. Matiello M, et al. Genetic analysis of aquaporin-4 in neuromyelitis optica. Neurology. 2011; 77:1149-1155. [PubMed: 21900637]

143. Kleffner I, et al. The role of aquaporin-4 polymorphisms in the development of brain edema after middle cerebral artery occlusion. Stroke. 2008; 39:1333-1335. [PubMed: 18309154]

144. Heuser K, et al. Variants of the genes encoding AQP4 and Kir4.1 are associated with subgroups of patients with temporal lobe epilepsy. Epilepsy Res. 2010; 88:55-64. [PubMed: 19864112]

145. Ma T, et al. Generation and phenotype of a transgenic knockout mouse lacking the mercurialinsensitive water channel aquaporin-4. J Clin Invest. 1997; 100:957-962. [PubMed: 9276712]

146. Fan Y, et al. Sex- and region-specific alterations of basal amino acid and monoamine metabolism in the brain of aquaporin-4 knockout mice. J Neurosci Res. 2005; 82:458-464. [PubMed: 16237719]

147. Saadoun S, et al. AQP4 gene deletion in mice does not alter blood-brain barrier integrity or brain morphology. Neuroscience. 2009; 161:764-772. [PubMed: 19345723]

148. Binder DK, Papadopoulos MC, Haggie PM, Verkman AS. In vivo measurement of brain extracellular space diffusion by cortical surface photobleaching. J Neurosci. 2004; 24:8049_ 8056. [PubMed: 15371505]

149. Zhang H, Verkman AS. Microfiberoptic measurement of extracellular space volume in brain and tumor slices based on fluorescent dye partitioning. Biophys J. 2010; 99:1284-1291. [PubMed: 20713014]

150. Yao X, Hrabetova S, Nicholson C, Manley GT. Aquaporin-4-deficient mice have increased extracellular space without tortuosity change. J Neurosci. 2008; 28:5460-5464. [PubMed: 18495879]

151. Eilert-Olsen M, et al. Deletion of aquaporin-4 changes the perivascular glial protein scaffold without disrupting the brain endothelial barrier. Glia. 2012; 60:432-440. [PubMed: 22131281]

152. Zeng XN, et al. Aquaporin-4 deficiency down-regulates glutamate uptake and GLT-1 expression in astrocytes. Mol Cell Neurosci. 2007; 34:34-39. [PubMed: 17074507]

153. Li L, Zhang H, Varrin-Doyer M, Zamvil SS, Verkman AS. Proinflammatory role of aquaporin-4 in autoimmune neuroinflammation. FASEB J. 2011; 25:1556-1566. [PubMed: 21257712]

154. Skucas VA, et al. Impairment of select forms of spatial memory and neurotrophin-dependent synaptic plasticity by deletion of glial aquaporin-4. J Neurosci. 2011; 31:6392-6397. [PubMed: 21525279]

155. Benfenati V, et al. An aquaporin-4/transient receptor potential vanilloid 4 (AQP4/TRPV4) complex is essential for cell-volume control in astrocytes. Proc Natl Acad Sci USA. 2011; 108:2563-2568. [PubMed: 21262839]

156. Li Z, et al. Aquaporin-4 knockout regulated cocaine-induced behavior and neurochemical changes in mice. Neurosci Lett. 2006; 403:294-298. [PubMed: 16797122]

157. Fan Y, et al. Aquaporin-4 promotes memory consolidation in Morris water maze. Brain Struct Funct. 2013; 218:39-50. [PubMed: 22193336] 
158. Yang W, et al. Aquaporin-4 mediates astrocyte response to $\beta$-amyloid. Mol Cell Neurosci. 2012; 49:406-414. [PubMed: 22365952]

159. Amiry-Moghaddam M, et al. Brain mitochondria contain aquaporin water channels: evidence for the expression of a short AQP9 isoform in the inner mitochondrial membrane. FASEB J. 2005; 19:1459-1467. [PubMed: 16126913]

160. Bennett JL, et al. Intrathecal pathogenic anti-aquaporin-4 antibodies in early neuromyelitis optica. Ann Neurol. 2009; 66:617-629. [PubMed: 19938104] 
a
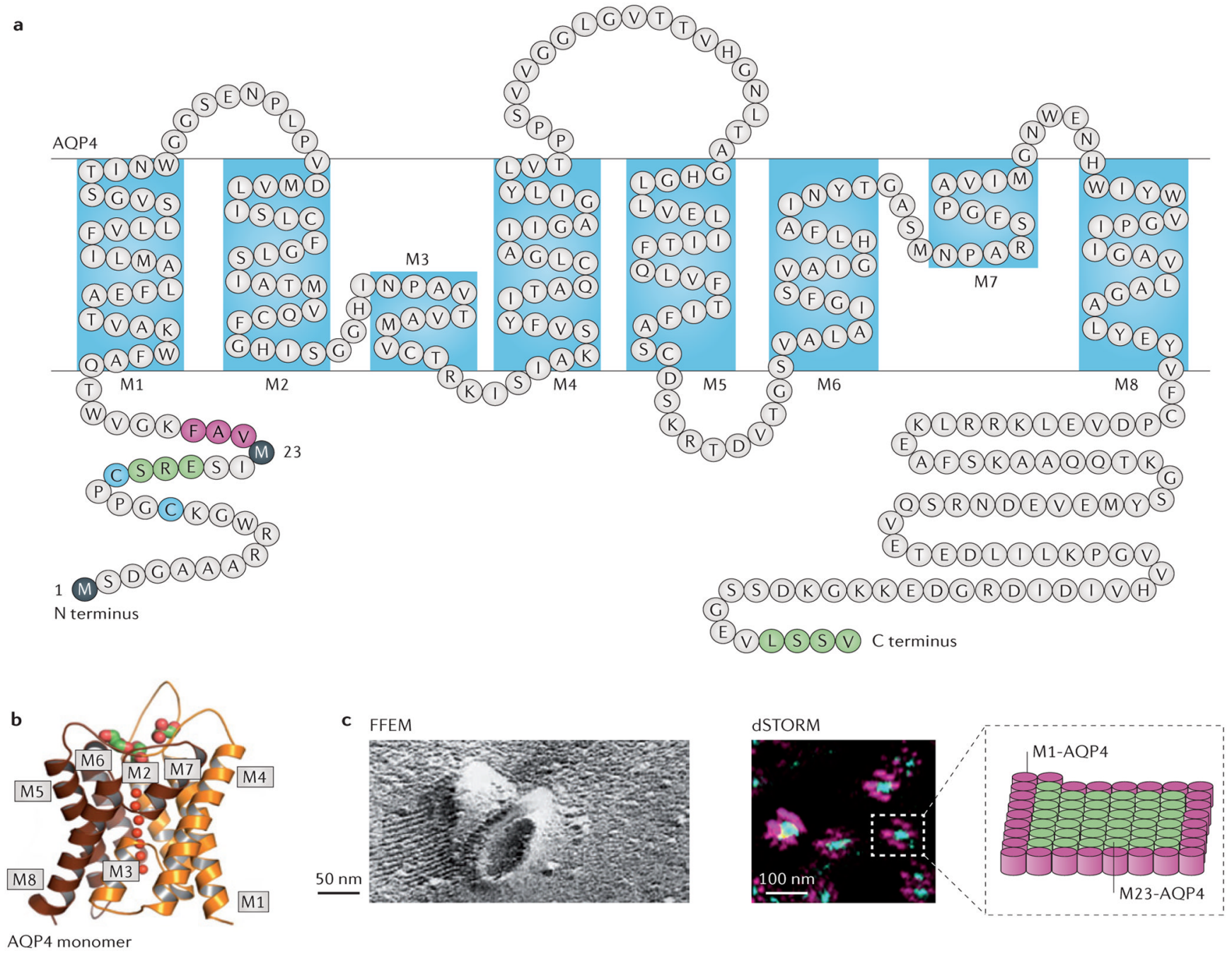

Figure 1. Sequence and structural features of AQP4

a The schematic depicts the primary amino acid sequence and membrane topology of aquaporin 4 (AQP4). This AQP has eight membrane-embedded helical segments, which are labelled M1-M8, and two translation initiation sites - Met1 and Met23 (black) corresponding to the two AQP4 isoforms, M1 and M23, respectively. AQP4 tetramers can form orthogonal arrays of particles (OAPs) through intermolecular N-terminal associations between M23 isoforms involving the residues highlighted in purple. The residues in green prevent N-terminal associations between M1 AQP4 molecules. Cysteine residues (in blue) are sites of palmitoylation, and are involved in regulating OAP assembly. The $\mathrm{C}$ terminus of AQP4 contains a PDZ domain (in green) that may be involved in protein-protein interactions. b | X-ray crystal structure of human AQP4 (RCSB Protein Data Bank ID: 3GD8) shows the eight membrane-embedded helical segments. c $\mid$ Freeze-fracture electron micrograph (FFEM) of M23-AQP4-expressing Chinese hamster ovary cells shows that AQP4 OAPs are supermolecular assemblies that have a cobblestone-like array structure (left panel $)^{14}$. The middle panel shows a super-resolution micrograph, which was obtained by direct stochastic optical reconstruction microscopy (dSTORM), of cells co-expressing a green fluorescent variant of M23-AQP4 and a red fluorescent variant of M1-AQP4 (REF. 18). From such micrographs, it has been determined that OAPs have a M23-AQP4-enriched core, with M1-AQP4 being found in the periphery of these structures (diagrammatically 
depicted in the inset on the right). The left panel of part $\mathbf{c}$ is reproduced, with permission, from REF. 14 ๑ (1996) American Society for Biochemistry and Molecular Biology. The middle and right panels in part $\mathbf{c}$ are modified, with permission, from REF. 18 () (2012) The Company of Biologists Ltd. 


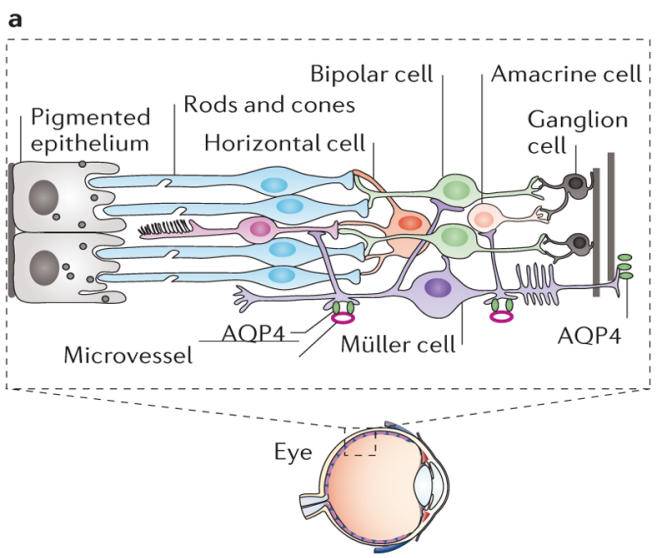

b

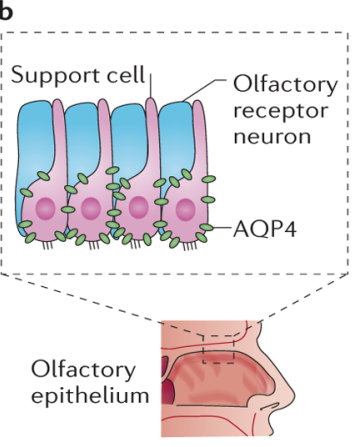

d

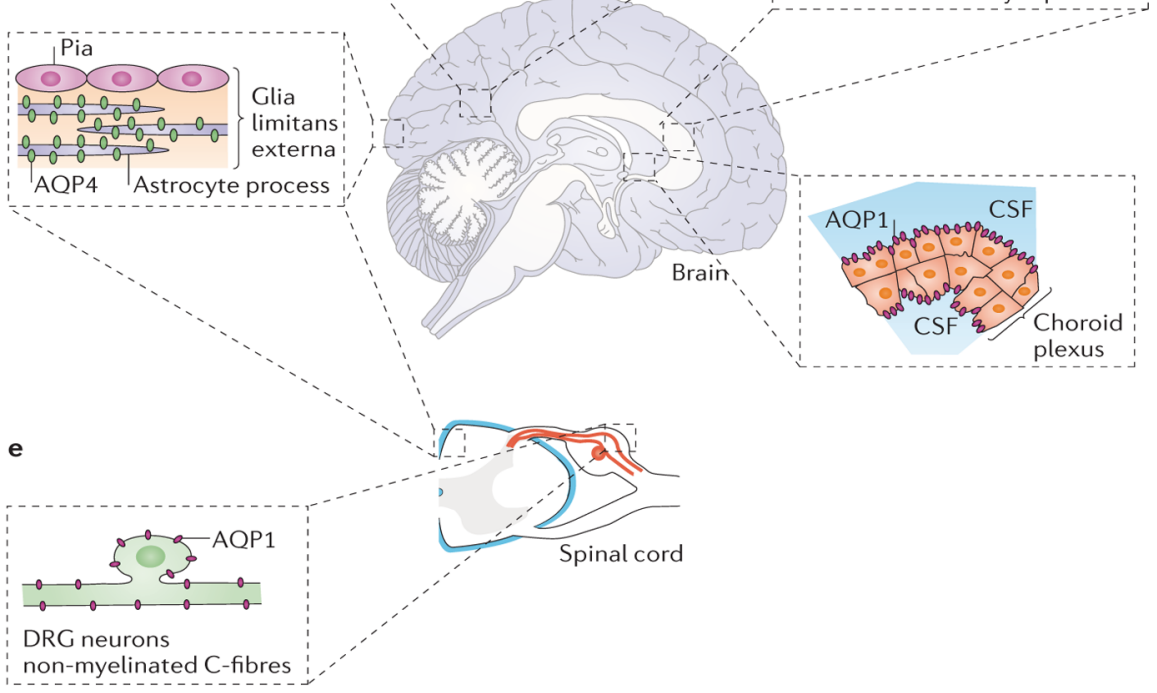

Figure 2. Aquaporin expression in the nervous system c

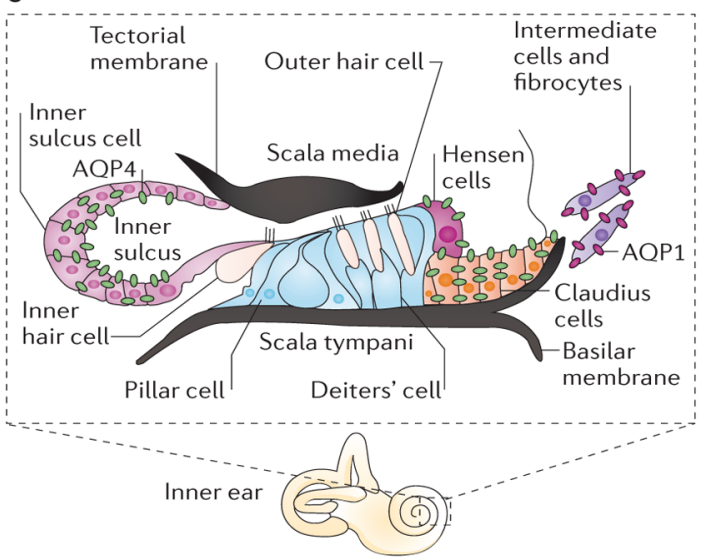

Enteric system !
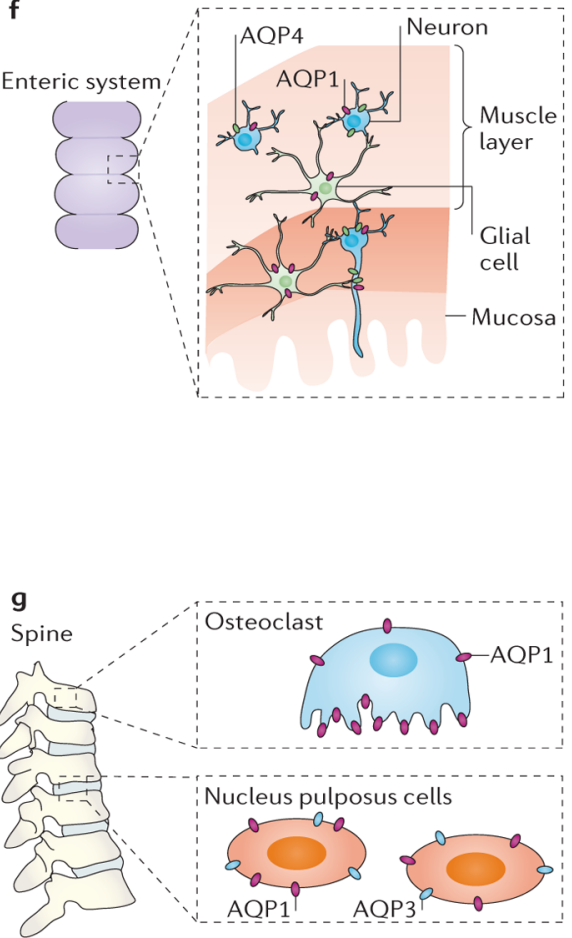

a In the retina, aquaporin 4 (AQP4) is expressed in its vitreous-facing ciliary epithelium and in perivascular processes of Müller cells. $\mathbf{b} \mid$ In the olfactory epithelium, AQP4 is expressed in olfactory epithelium support cells. $\mathbf{c} \mid$ In the inner ear, AQP4 can be detected in the inner sulcus, and in Claudius and Hensen cells in the cochlea, and AQP1 can be found in intermediate cells and fibrocytes of the spiral ligament. $\mathbf{d} \mid$ In the brain, AQP4 is primarily expressed in astrocyte processes of the glia limitans externa and perivascular astrocyte foot processes. AQP4 is also expressed in the basolateral cell plasma membrane of ependymal cells and in subependymal astrocyte processes of the glia limitans externa. AQP1 is expressed in the cerebrospinal fluid (CSF)-facing plasma membrane of the choroid plexus epithelium. The sites of AQP9 expression remain unclear. $\mathbf{e} \mid$ In the spinal cord, AQP1 is expressed in non-myelinated dorsal root ganglion (DRG) neurons, whereas AQP4 is expressed in astrocyte processes of the glia limitans externa and in perivascular astrocyte foot processes. $\mathbf{f} \mid$ In the enteric nervous system, AQP1 is expressed in glia, whereas AQP4 
is found in neurons and glia of the submucosal and myenteric plexuses. $\mathbf{g} \mid$ In the spine, AQP9 is expressed in osteoclasts within the vertebrae, and AQP1 and AQP3 are found in nucleus pulposus cells. 


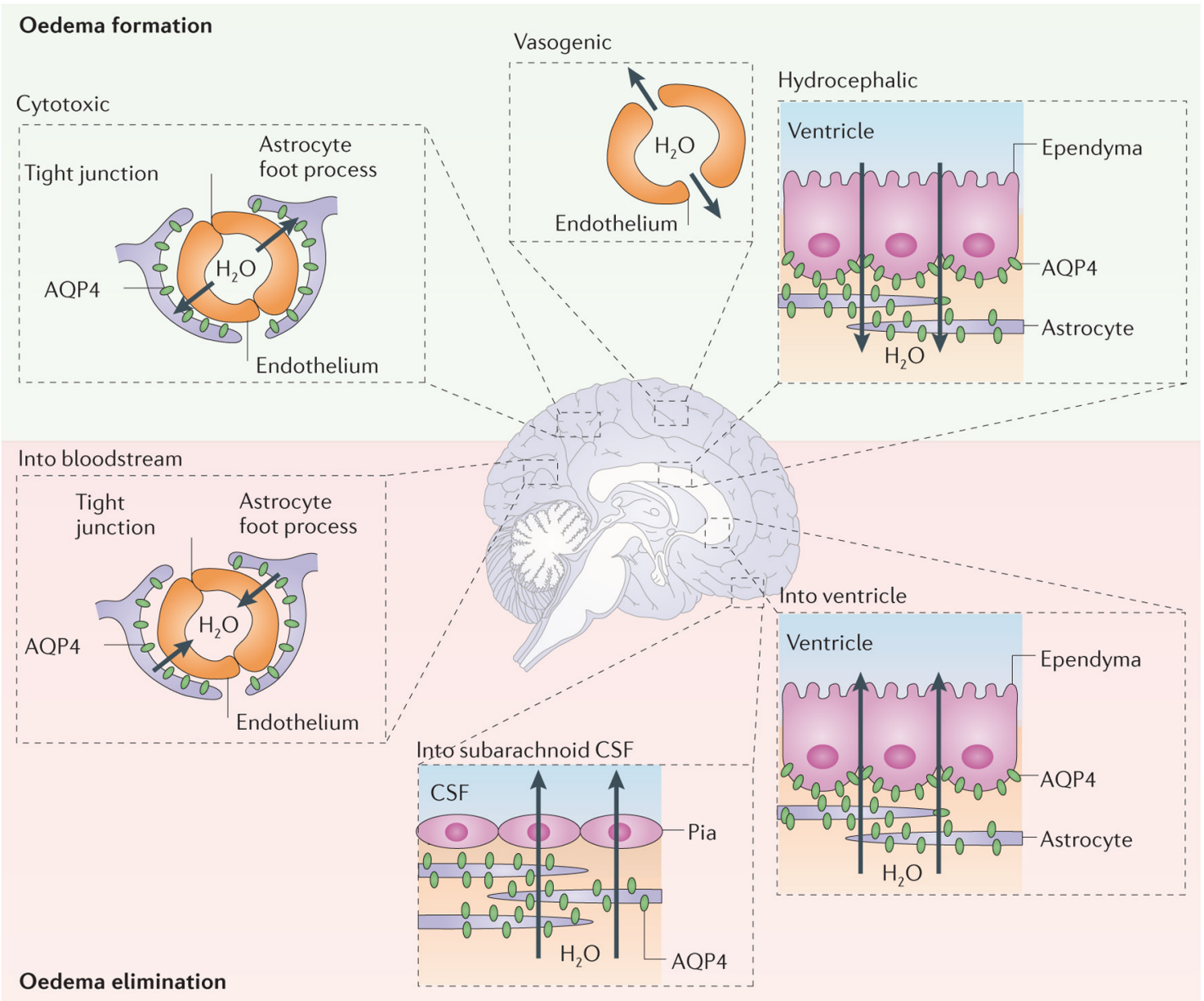

Figure 3. Routes of water flow into and out of the CNS in brain oedema In cytotoxic oedema, water enters the CNS through aquaporin 4 (AQP4) that is located in perivascular astrocyte foot processes. In vasogenic oedema, CNS water entry is AQP4independent and occurs through intercellular spaces. In hydrocephalic oedema, water enters the brain through AQP4 in ependymal cells and subependymal astrocytes. Oedema fluid is eliminated through three AQP4-dependent routes: from astrocyte foot processes into the bloodstream, across subpial astrocyte processes and pial cells into subarachnoid cerebrospinal fluid (CSF), and across subependymal astrocyte processes and ependyma into ventricle. 
a

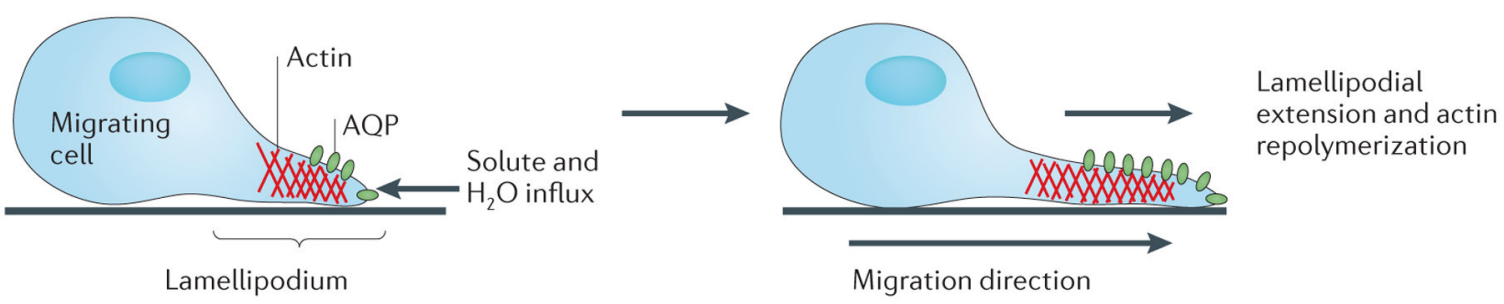

b

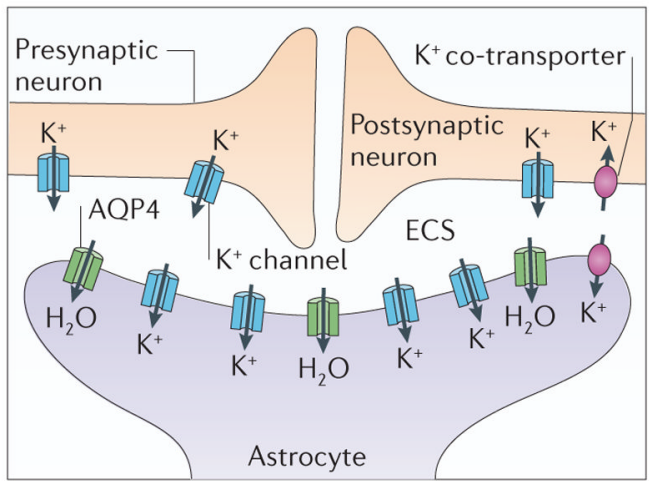

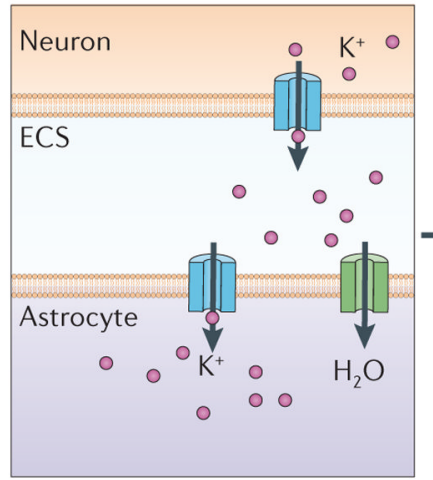

Neuroexcitation

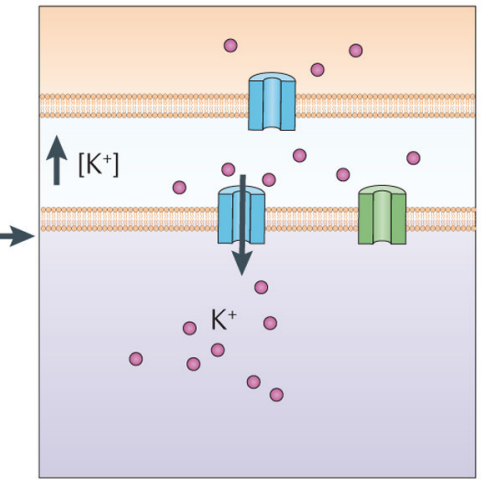

Early post-neuroexcitation

Figure 4. Aquaporin 4 involvement in astrocyte migration and neuroexcitation

a Aquaporin 4 (AQP4) has a proposed role in astrocyte migration. Water is driven into the cytoplasm primarily through AQP4 in the lamellipodium by an osmotic gradient created by actin depolymerization and active solute influx (left), facilitating lamellipodial extension in the direction of cell migration (right). $\mathbf{b}$ | AQP4 is also proposed to have a role in neuroexcitation outside the synaptic cleft (left panel). Neuroexcitation involves isosmolar $\mathrm{K}^{+}$release by neurons and uptake of $\mathrm{K}^{+}$and water by astrocytes (centre panel). AQP4 facilitates water entry into astrocytes, resulting in contraction of the extracellular space (ECS) volume and increased ECS $\mathrm{K}^{+}$concentration $\left(\left[\mathrm{K}^{+}\right]\right.$; right panel), which further drives astrocyte $\mathrm{K}^{+}$uptake. 
a

Complement activation Astrocyte damage

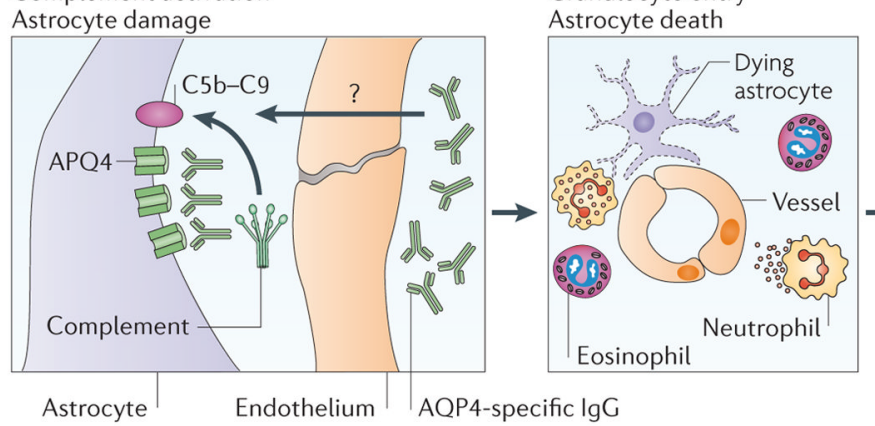

C

Macrophage entry

Pan-necrosis

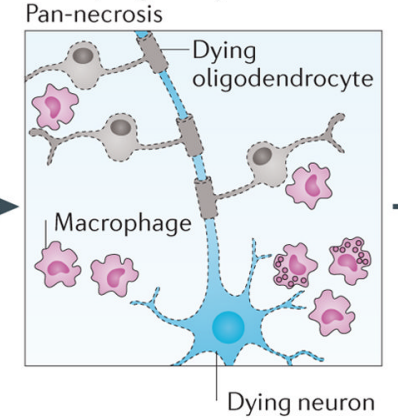

\section{d}

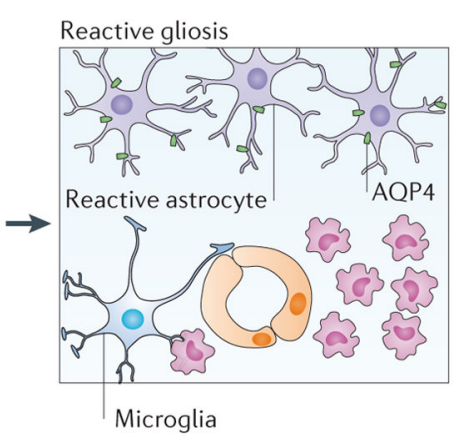

Figure 5. Proposed role of aquaporin 4 in the pathogenesis of neuromyelitis optica a $\mid$ Circulating aquaporin 4 (AQP4)-specific immunoglobulin $\mathrm{G}(\mathrm{IgG})$ enters the CNS and binds to AQP4 on astrocyte foot processes. Complement is activated via the classical pathway with deposition of $\mathrm{C} 5 \mathrm{~b}-\mathrm{C} 9$ complexes in astrocyte cell plasma membranes. $\mathbf{b}$ | Activated complement components attract peripheral leukocytes (primarily neutrophils and eosinophils) into the lesion, which degranulate, causing astrocyte death. $\mathbf{c} \mid$ Chemokines (from dying astrocytes and activated leukocytes) attract macrophages, causing death of oligodendrocytes and neurons. d | Microglia enter the lesion as well as reactive astrocytes, which express AQP4 and form a glial scar. The lesion core is necrotic with a macrophage infiltrate. 